Florida International University

FIU Digital Commons

FIU Electronic Theses and Dissertations

University Graduate School

7-2-2014

\title{
The Relationships between Elementary School Principals' Emotional Intelligence, Leadership Style and School Culture
}

Mirta R. Segredo

Florida International University, msegredo@dadeschools.net

DOI: $10.25148 /$ etd.FI14071124

Follow this and additional works at: https://digitalcommons.fiu.edu/etd

\section{Recommended Citation}

Segredo, Mirta R., "The Relationships between Elementary School Principals' Emotional Intelligence, Leadership Style and School Culture" (2014). FIU Electronic Theses and Dissertations. 1457.

https://digitalcommons.fiu.edu/etd/1457

This work is brought to you for free and open access by the University Graduate School at FIU Digital Commons. It has been accepted for inclusion in FIU Electronic Theses and Dissertations by an authorized administrator of FIU Digital Commons. For more information, please contact dcc@fiu.edu. 


\section{FLORIDA INTERNATIONAL UNIVERSITY \\ Miami, Florida}

THE RELATIONSHIPS BETWEEN ELEMENTARY SCHOOL PRINCIPALS'

EMOTIONAL INTELLIGENCE, LEADERSHIP STYLE

AND SCHOOL CULTURE

A dissertation submitted in partial fulfillment of

the requirements for the degree of

DOCTOR OF EDUCATION

in

EDUCATIONAL ADMINISTRATION AND SUPERVISION

by

Mirta R. Segredo

2014 
To: Dean Delia C. Garcia

College of Education

This dissertation, written by Mirta R. Segredo, and entitled The Relationships between Elementary School Principals' Emotional Intelligence, Leadership Style and School Culture, having been approved in respect to style and intellectual content, is referred to you for judgment.

We have read this dissertation and recommend that it be approved.

\author{
Delia C. Garcia \\ Thomas G. Reio \\ Linda A. Spears-Bunton \\ Joan Wynne \\ Peter J. Cistone, Major Professor
}

Date of Defense: July $2^{\text {nd }}, 2014$

The dissertation of Mirta R. Segredo is approved.

Dean Delia C. Garcia
College of Education

Dean Lakshmi N. Reddi

University Graduate School

Florida International University, 2014 
(C) Copyright 2014 by Mirta R. Segredo

All rights reserved. 


\section{DEDICATION}

For my children, Cristina and Frankie, my greatest source of both pride and inspiration. 


\section{ACKNOWLEDGMENTS}

To have finally realized a goal decades after having originally defined it is immensely rewarding. The bonds formed with the professionals integral to the process have been the most gratifying aspect of this endeavor. I am indebted to the members of my committee for their consistent guidance, support and encouragement.

Dr. Joan Wynne's contagiously uplifting spirit projects an encouraging aura that minimized the magnitude of the work involved. Dr. Linda A. Spears-Bunton's creative approach to conceptualizing and discussing educational issues broadened our perspectives as students and challenged us to think outside the box.

Special thanks must go to Dean Delia C. Garcia. Her consistent encouragement and contributions have been vital. Her vision and dedication to serving the FIU community, which resulted in the Creating Latino Access to a Valuable Education (CLAVE) Grant award, made it possible for me and several other Hispanic educators to pursue advanced degrees.

Dr. Thomas G. Reio afforded me the opportunity to collaborate on a research project, and on the presentation of this work at the American Educational Research Association (AERA) national meeting in April, 2013. Dr. Reio was also instrumental in helping me navigate the data analysis process. I am extremely grateful for his role in my professional development, and in enabling me to bring this dissertation to fruition.

I must also thank my major professor, Dr. Peter J. Cistone, for his guidance and encouragement. His consistent support was palpable, and enabled me to focus on the work involved knowing that he was committed to facilitating the process. His expertise in the topic of my study was also vital in formulating and developing this dissertation. 
Finally, I would like to thank the principals and teachers of Miami-Dade County Public Schools who willingly donated their time to participate in this study. Without their commitment to education and to educational research, this study would not have been possible. 


\title{
ABSTRACT OF THE DISSERTATION \\ THE RELATIONSHIPS BETWEEN ELEMENTARY SCHOOL PRINCIPALS' \\ EMOTIONAL INTELLIGENCE, LEADERSHIP STYLE \\ AND SCHOOL CULTURE
}

\author{
by \\ Mirta R. Segredo \\ Florida International University, 2014 \\ Miami, Florida \\ Professor Peter J. Cistone, Major Professor
}

The role of the principal in school settings and the principal's perceived effect on student achievement have frequently been considered vital factors in school reform. The relationships between emotional intelligence, leadership style and school culture have been widely studied. The literature reveals agreement among scholars regarding the principal's vital role in developing and fostering a positive school culture. The purpose of this study was to explore the relationships between elementary school principals' emotional intelligence, leadership style and school culture.

The researcher implemented a non-experimental ex post facto research design to investigate four specific research hypotheses. Utilizing the Qualtrics Survey Software, 57 elementary school principals within a large urban school district in southeast Florida completed the Emotional Quotient Inventory (EQ-i), and 850 of their faculty members completed the Multifactor Leadership Questionnaire (MLQ Form 5X). Faculty responses to the school district's School Climate Survey retrieved from the district's web site were used as the measure of school culture. 
Linear regression analyses revealed significant positive associations between emotional intelligence and the following leadership measures: Idealized InfluenceAttributes $(\beta=.23, p=<.05)$, Idealized Influence-Behaviors $(\beta=.34, p=<.01)$, Inspirational Motivation $(\beta=.39, p=<.01)$ and Contingent Reward $(\beta=.33, p=<.01)$. Hierarchical regression analyses revealed positive associations between school culture and both transformational and transactional leadership measures, and negative associations between school culture and passive-avoidant leadership measures. Significant positive associations were found between school culture and the principals' emotional intelligence over and above leadership style. Hierarchical linear regressions to test the statistical hypothesis developed to account for alternative explanations revealed significant associations between leadership style and school culture over and above school grade.

These results suggest that emotional intelligence merits consideration in the development of leadership theory. Practical implications include suggestions that principals employ both transformational and transactional leadership strategies, and focus on developing their level of emotional intelligence. The associations between emotional intelligence, transformational leadership, Contingent Reward and school culture found in this study validate the role of the principal as the leader of school reform. 


\section{TABLE OF CONTENTS}

CHAPTER

PAGE

I. INTRODUCTION.........................................................

Purpose Statement and Significance of the Study .......................... 5

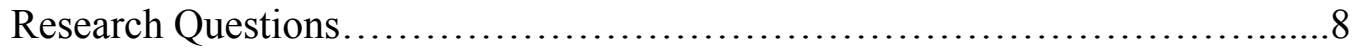

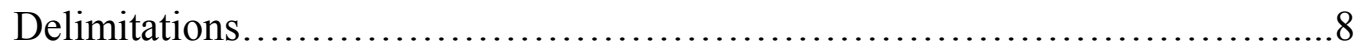

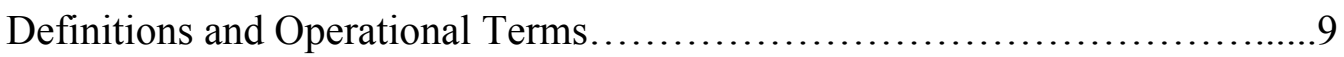

II. REVIEW OF THE LITERATURE...........................................13

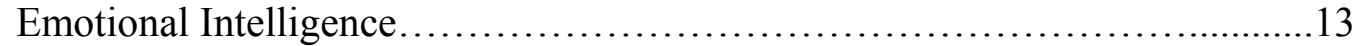

Transformational Leadership............................................22

Transformational Leadership and Emotional Intelligence......................29

Principals, Transformational Leadership and School Culture....................33

Emotional Intelligence, Transformational Leadership and School Culture.......36

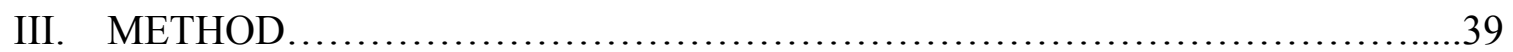

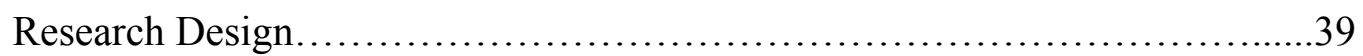

General and Specific Hypotheses............................................. 41

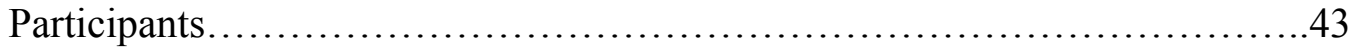

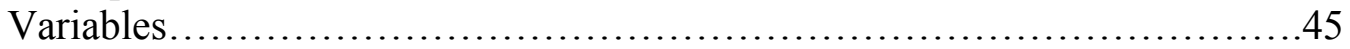

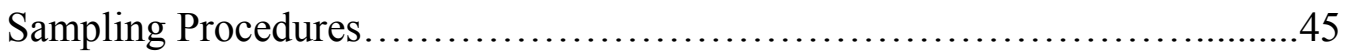

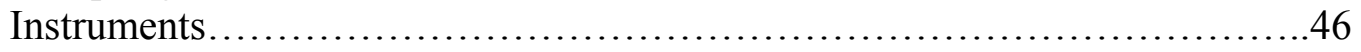

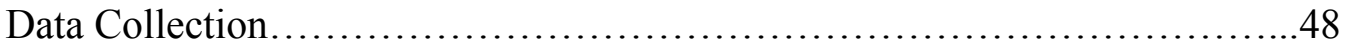

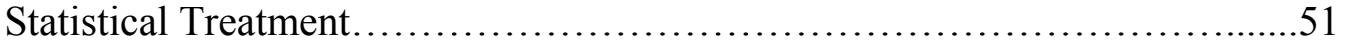

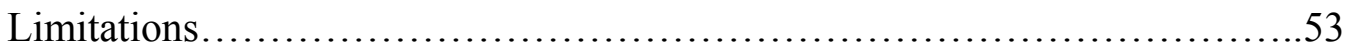

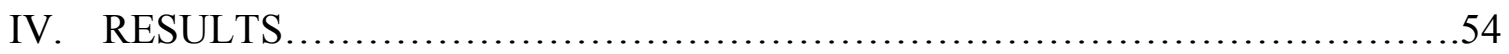

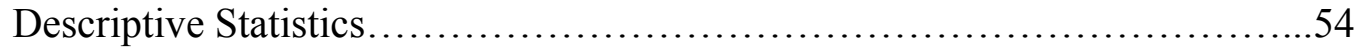

Results of Testing the Research Hypotheses.................................60

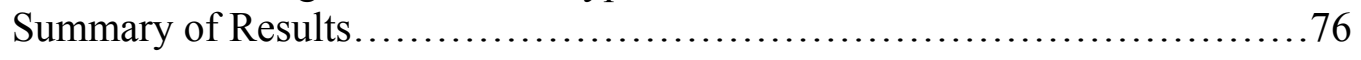

V. SUMMARY, CONCLUSIONS, AND IMPLICATIONS .......................78

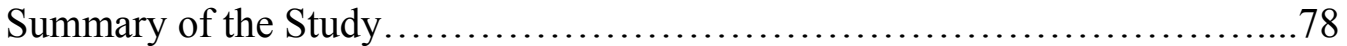

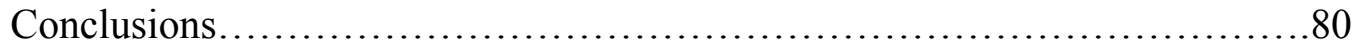

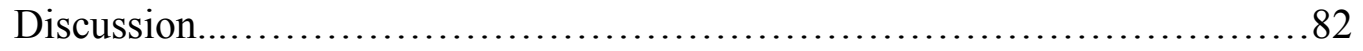

Suggested Further Research................................................91

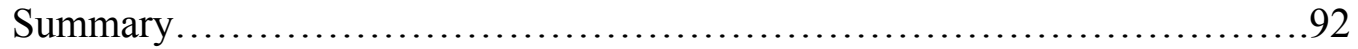

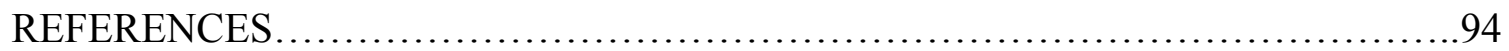

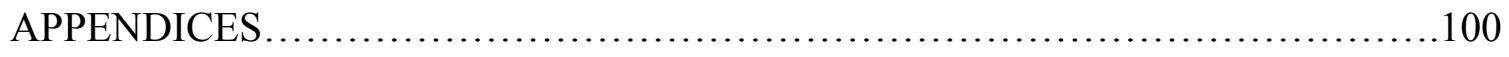

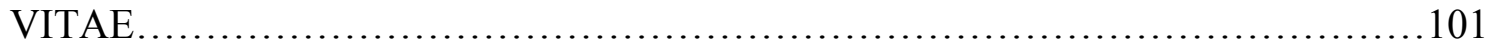




\section{LIST OF TABLES}

Table

PAGE

1. Summary of Principal and Teacher Demographics...............................44

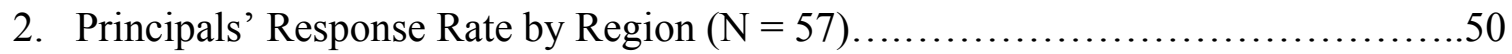

3. Faculty Percentage of Response Rates per School $(\mathrm{N}=57) \ldots \ldots \ldots \ldots \ldots \ldots \ldots \ldots \ldots$

4. Summary of the EQ-i Standard Scores for Principals for the 5 Categories

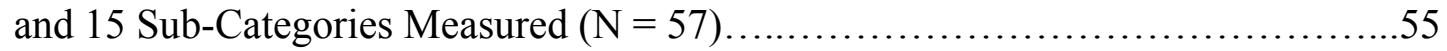

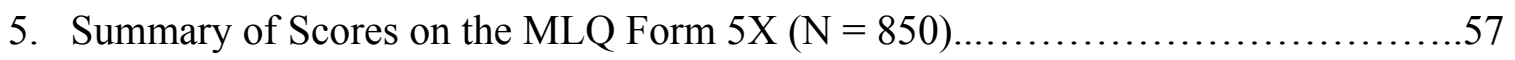

6. Summary of the School Climate Survey Results $\left(\mathrm{N}=56^{*}\right) \ldots \ldots \ldots \ldots \ldots \ldots \ldots \ldots \ldots . \ldots \ldots$

7. Summary of School Grades Assigned in Florida's

Accountability Reports $(\mathrm{N}=57)$.

8. Summary of Linear Regressions with Emotional Intelligence

Predicting Leadership $(\mathrm{N}=57)$.

9. Linear Regression of the Interaction of Leadership and Emotional Intelligence

Predicting School Culture $(\mathrm{N}=57)$.

10. Summary of Hierarchical Regression Analysis for Transformational Leadership

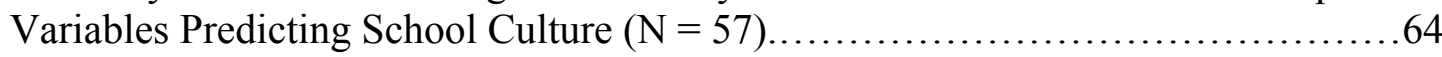

11. Summary of Hierarchical Regression Analysis for Transactional Leadership Variables Predicting School Culture $(\mathrm{N}=57)$.

12. Summary of Hierarchical Regression Analysis for Passive-Avoidant Leadership Variables Predicting School Culture $(\mathrm{N}=57)$.

13. Summary of Hierarchical Regression Analysis for Emotional Intelligence Predicting School Culture Over and Above Transformational Leadership Variables $(\mathrm{N}=57)$.

14. Summary of Hierarchical Regression Analysis for Emotional Intelligence Predicting School Culture Over and Above Transactional Leadership Variables $(\mathrm{N}=57)$. 
15. Summary of Hierarchical Regression Analysis for Emotional Intelligence Predicting School Culture Over and Above Passive-Avoidant Leadership Variables $(\mathrm{N}=57)$

16. Summary of Hierarchical Regression Analysis for School Grade Predicting School Culture Over and Above Transformational Leadership

Variables $(\mathrm{N}=57)$

17. Summary of Hierarchical Regression Analysis for School Grade Predicting School Culture Over and Above Transactional Leadership Variables $(\mathrm{N}=57)$

18. Summary of Hierarchical Regression Analysis for School Grade Predicting School Culture Over and Above Passive-Avoidant Leadership Variables $(\mathrm{N}=57)$ 


\section{CHAPTER I \\ INTRODUCTION}

The role of the principal in school settings and the principal's perceived effect on student achievement have frequently been considered vital factors in school reform and the quest for improved student performance (Fullan, 2002; Witziers, Bosker, \& Krüger, 2003). Witziers et al. (2003) emphasized the fact that internationally, principals are increasingly being held accountable for the success or failure of their students. Fullan (2002) indicated that effective school leadership is the key to sustainable, large-scale school reform. Leadership theory and the practices that have been applied in school settings have historically reflected the management and organizational theories prevalent at the time. The perceived role of school leaders has evolved from that of managers and supervisors unquestionably in charge when classical organizational theory prevailed in the 1900 s, to the current views calling for instructional leaders exhibiting transformational leadership behaviors (Hallinger, 2003).

James MacGregor Burns' seminal publication of Leadership in 1978 introduced the concept of transformational leadership. Burns (1978) believed that individuals in leadership positions should address the higher-level needs of their followers. Citing the hierarchies developed by Maslow and Kohlberg, Burns identified esteem, competency, self-fulfillment and self-actualization as the higher-level needs on which leaders should focus. By doing so, leaders possess the capacity to change, or transform, the nature of their followers; but, moreover, according to Burns, leaders have a moral commitment to do so. As Burns indicated, the "result of transforming leadership is a relationship of 
mutual stimulation and elevation that converts followers into leaders and may convert leaders into moral agents" (p. 4).

Burns contrasted transformational leadership behavior with transactional leadership, in which the focus is on the lower-level needs described by Maslow. Traditional leadership, Burns believed, was transactional in nature. That is, leadership consisted of a series of exchanges between leaders and followers. Leaders provided money, benefits, recognition and other rewards in exchange for the desired behavior of the followers. Burns believed that leaders employ either transactional or transformational strategies, and advocated for the implementation of transformational leadership strategies.

On the other hand, Bass and Avolio (1994) found that transformational leaders employ both transactional and transformational techniques. They elaborated on Burns' work and identified specific characteristics of transactional and transformational types of leadership. Transactional leadership includes both passive and active elements. Active transactional leadership techniques include contingent reward and management-byexception. That is, rewards and recognition are contingent upon followers meeting stated objectives, and disciplinary techniques are employed when objectives are not met. Passive-avoidant or laissez-faire leadership practices are characteristic of leaders who fail to take action even when problems arise, and do not provide clear goals or expectations.

Bass and Avolio (1994) felt that active transactional leadership elements were employed by leaders who also utilized transformational leadership strategies, and delineated specific strategies attributed to transformational leaders. These included 
idealized influence, inspirational motivation, intellectual stimulation and individualized consideration. Idealized influence is exemplified by leaders who become role models. They earn the respect and admiration of their followers by placing their followers' needs above their own, and by behaving in a manner that is consistent with the goals and values of the group. Inspirational and intellectual stimulation is provided by transformational leaders who are enthusiastic, optimistic and generate "espirit de corps" among their followers, while encouraging innovation, creativity and input from followers. Finally, transformational leaders demonstrate individualized consideration for their followers when they act as coaches or mentors and foster their followers' personal development.

According to Bass and Avolio, transformational leaders utilize these strategies in conjunction with the active elements of transactional leadership of contingent reward and management-by-exception. Consistent with these views, they developed an instrument to measure the degree to which leaders exhibit transformational, transactional and passiveavoidant dimensions of leadership style (Bass \& Avolio, 1994). The Multifactor Leadership Questionnaire (MLQ Form 5X), which has been used extensively in research and is considered a strong predictor of leader behavior (Lindebaum \& Cartwright, 2010), was the measure of leadership style utilized in this study.

The relationship between leadership style and emotional intelligence has been addressed in the literature and merits further research (Barbuto \& Burbach, 2006; Butler \& Chinowsky, 2006; Duckett \& Macfarlane, 2003; Leban \& Zulauf, 2004; Weinberger, 2009). Emotional intelligence was originally conceived of and defined as an abilitybased construct involving the ability to perceive emotions, use emotions to facilitate 
thought, understand emotion, and regulate emotions to achieve goals (Mayer \& Salovey, 1997). Subsequent theorists developed a trait-based definition of emotional intelligence and defined it as "an array of noncognitive capabilities, competencies, and skills that influence one's ability to succeed in coping with environmental demands and pressures" (Bar-On, 1997, p. 14). The Bar-On Emotional Quotient Inventory (EQ-i) is a self-report survey developed to measure the degree to which individuals exhibit these traits. This instrument provides a total score as well as scores form four composite scales measuring intrapersonal skills, interpersonal skills, adaptability and stress management (Bar-On, 1997). The EQ-i was the measure of emotional intelligence utilized in this study.

Questions raised among scholars of leadership theory regarding the relationship between leadership style and emotional intelligence have not been conclusively resolved (Antonakis, 2003; Fullan, 2002; Prati, Douglas, Ferris, Ammeter, \& Buckley, 2003). However, because a high level of emotional intelligence has been considered a possible antecedent of transformational leadership, further exploration of this relationship was warranted (Brown \& Moshavi, 2005).

Hallinger's (2003) call for school leaders to employ a transformational leadership style has been supported by empirical research which revealed the principal's impact on school culture or cultural norms (Kelley, Thornton \& Daugherty, 2005). Culture has been defined as "the underground stream of norms, values, beliefs, traditions, and rituals that has built up over time" (Peterson \& Deal, 1998, p. 28). The key to building a positive culture is to first read and understand the existing culture, articulate values, and foster positive values while modifying negative values. Other researchers offered thoughts on 
strategies for building a positive school culture as well, stressing the importance of rituals and ceremony (Rud \& Garrison, 2010), and the importance of celebrating accomplishments (Davies \& Brighouse, 2010). Witziers et al. (2003) discussed not only leaders' roles in shaping school culture, but also the notion of reciprocity. That is, "leaders not only shape cultures, but adapt to them" (p. 416) —a concept that reinforces the importance of the character and qualities of school leaders, and is aligned with Burns' (1978) perception that "transforming leadership is a relationship of mutual stimulation and elevation" (p. 4).

Thus, while the difficulty of changing a school's norms and/or culture has been recognized (Fullan, 2001), researchers have indicated that these outcomes can be achieved by employing a transformational leadership style (Bass \& Avolio, 1994; Burns, 1978). Furthermore, if by employing transformational leadership styles principals can transform school culture, and if emotional intelligence is pivotal in determining the leadership style employed, then exploring the relationship between emotional intelligence, leadership style and school culture is vital. These relationships just might hold the key toward successful school reform.

\section{Purpose Statement and Significance of the Study}

Ample debate is evident in the literature vis-à-vis the conceptualization of emotional intelligence (Petrides \& Furnham, 2003), as well as the distinction between leadership practices that involve transactional and transformational leadership behaviors (Bass \& Avolio, 1994; Burns, 1978). The prevailing thought is that leaders who are considered to exemplify transformational practices, also at times utilize transactional 
strategies; and, moreover, that a transformational approach is the most effective and appropriate style in school leadership (Barth, 2002; Fullan, 2002; Hallinger, 2003; Leithwood, 1992, 1994). Empirical studies in various organizational settings have corroborated a relationship between emotional intelligence and transformational leadership style (Butler \& Chinowsky, 2006; Duckett \& Macfarlane, 2003; Leban \& Zulauf, 2004).

A question with practical implications emerges regarding the preparation and development of school leaders who employ transformational leadership practices. The connection between emotional intelligence and transformational leadership becomes a key factor in this question because it has been suggested that emotional intelligence may be an antecedent of transformational leadership (Brown \& Moshavi, 2005), and that emotional intelligence is a skill that can be developed (Nelson, Low, \& Ellis, 2007).

The effect of transformational leadership in school settings has been attributed to its influence on organizational culture (Hallinger, 2003). The transformative power of this leadership style is contingent upon the relationship between leaders and followers (Fullan, 2002; Leithwood, 1992). These transformed relationships are vital in achieving school reform and school restructuring, and in moving toward the professionalization of teaching (Leithwood, 1994). Principals leading these reform movements should consciously consider the emotional impact of change on teachers (Reio, 2005). Here, again, the principal's emotional intelligence could play a key role in navigating through the changes inherent in the process of school reform (Fullan, 2002; Goleman, 1998a). Ultimately, a principal's effect on the school's culture leads to an impact on student achievement (Witziers et al., 2003). The significance of a principal's ability to 
successfully achieve these results by adopting an effective leadership style is magnified in the current context of schools in which the principals' role and authority is diminished by the increasingly stringent accountability measures resulting from legislative intrusion through the No Child Left Behind Act of 2001 (Conley, 2003).

Additional research is required prior to tapping the potentially promising practical applications implicit in the association between emotional intelligence and transformational leadership, and the resulting effect on school culture. The purpose of this study was to explore the relationships between emotional intelligence, leadership style and organizational culture in school settings. Three data sources were utilized. The Bar-On Emotional Quotient Inventory (EQ-i) was the self-report method utilized to measure the trait EI of the principals. Faculty members completed the Multifactor Leadership Questionnaire (MLQ $5 \mathrm{X})$ as the measure of leadership style. The School Climate Survey developed by the school district in which the study was conducted was utilized to gather data regarding school culture. Prior research exploring the relationship between these constructs has proven inconclusive because statistically significant findings have been inconsistent (Barbuto \& Burbach, 2006; Butler \& Chinowsky, 2006; Duckett \& Macfarlane, 2003; Leban \& Zulauf, 2004; Weinberger, 2009). The support for a relationship between emotional intelligence and transformational leadership style found in this study serves to advance leadership theory (Brown and Moshavi, 2005), and provides practical applications in leadership development (Nelson et al., 2007). Thus, this study contributes to the knowledge base regarding these relationships by expanding on prior research and potentially paving the way for practical applications in school settings. 


\section{Research Questions}

Once data sources were gathered, an analysis of the data was conducted to address the following research questions:

1. Does the emotional intelligence of public elementary school principals account for a significant amount of unique variance in predicting leadership style?

2. Is there an interaction between the emotional intelligence of public elementary school principals and leadership style in predicting school culture?

3. Do the leadership style scores of elementary school principals account for a significant amount of unique variance in predicting their schools' culture independent of the principals' emotional intelligence?

4. Does the emotional intelligence of elementary school principals account for a significant amount of unique variance in predicting their schools' culture independent of their leadership style scores?

\section{Delimitations}

The sample selected for this investigation included elementary schools within a large urban school district in south Florida. The study was limited to the perceptions reported by the principals and teachers, and did not include all individuals within the school community, such as parents and students, in measuring school culture and leadership style. While these stakeholders' perspectives may provide an additional dimension to these constructs, because the transformative power of leaders is contingent upon the relationships developed with their followers (Fullan, 2002; Leithwood, 1992), the research focused on the leadership behaviors of the principals as perceived by 
teachers. Consequently, the measure of leadership style and school culture was limited to faculty perspectives.

\section{Definitions and Operational Terms}

\section{Ability Model Measures of Emotional Intelligence}

Ability model measures assess abilities and use a performance-based response format with pre-determined correct answers based on the percentage of respondents selecting specified options (Van Rooy \& Viswesvaran, 2007).

\section{Contingent Reward}

Contingent reward is an active component of transactional leadership which is also employed by transformational leaders (Bass \& Avolio, 1994). Leaders who utilize contingent reward provide rewards and recognition for followers who meet expected standards.

\section{Emotional Intelligence (Ability-based)}

Emotional intelligence is defined as the ability to perceive emotions, use emotions to facilitate thought, understand emotion, and regulate emotions to achieve goals (Mayer \& Salovey, 1997)

\section{Emotional Intelligence (Trait-based)}

Trait-based emotional intelligence is defined as a cluster of noncognitive skills or competencies that affect one's ability to successfully deal with environmental demands and pressures (Bar-On, 1997), and is operationally defined as the results of the Bar-On 
Emotional Quotient Inventory (EQ-i), a self-report instrument completed by the school principals in this study.

\section{Idealized Influence}

Idealized influence refers to a dimension of transformational leadership. Leaders who exercise idealized influence over their followers become role models, place their followers' needs above their own, earn the respect and admiration of their followers, and behave in manners that are consistent with the goals and values of the group (Bass \& Avolio, 1994).

\section{Individualized Consideration}

Individualized consideration is a dimension of transformational leadership. This dimension involves acting as coaches or mentors for followers, fostering personal development and providing learning opportunities (Bass \& Avolio, 1994).

\section{Inspirational Motivation}

Inspirational motivation is the dimension of transformational leadership that involves evoking team spirit through enthusiastic and optimistic behaviors that lead followers to develop a positive vision for the future (Bass \& Avolio, 1994).

\section{Intellectual Stimulation}

Intellectual stimulation is the dimension of transformational leadership that refers to leaders who encourage innovation, creativity and input from followers (Bass \& Avolio, 1994). 


\section{Management-by-Exception}

Management-by-exception is an active component of transactional leadership which is also employed by transformational leaders (Bass \& Avolio, 1994). Leaders who exercise management-by-exception utilize punitive measures when expected standards are not met by followers.

\section{Mixed Model or Trait-based Measures of Emotional Intelligence}

These measures of emotional intelligence assess aspects of personality and cognitive intelligence as well as emotional intelligence and are usually comprised of selfreport surveys (Van Rooy \& Viswesvaran, 2007).

\section{Passive-avoidant}

Passive-avoidant leadership practices are characteristic of leaders who fail to take action even when problems arise, and do not provide clear goals or expectations (Bass \& Avolio, 1994). Passive-avoidant leadership is operationally defined as the measures obtained on each of the passive-avoidant leadership dimensions included in the Multifactor Leadership Questionnaire (MLQ 5X) through teachers' responses for each of their respective principals.

\section{School Culture}

School culture refers to the shared beliefs about how a school should operate, core values regarding a school's goals for its students, and the behavioral norms exhibited by teachers (Maslowski, 2006). School culture is operationally defined in this study as the results of the School Climate Survey that was developed by the school district. 


\section{Transactional Leadership}

Transactional leadership refers to leadership practices in which leaders engage in an exchange with followers based on specified standards of acceptable performance (Johnson, 2012). Transactional leadership is operationally defined as the measures obtained on each of the transactional leadership dimensions included in the Multifactor Leadership Questionnaire (MLQ 5X) through teachers' responses for each of their respective principals.

\section{Transformational Leadership}

Transformational leadership is characterized as exhibiting four transformational dimensions: idealized influence, inspirational motivation, intellectual stimulation, and individualized consideration; and two active elements of transactional leadership: contingent reward, and management-by-exception (Bass \& Avolio, 1994).

Transformational leadership is operationally defined as the measures obtained on each of the transformational leadership dimensions included in the Multifactor Leadership Questionnaire (MLQ 5X) through teachers' responses for each of their respective principals. 


\section{CHAPTER II}

\section{REVIEW OF THE LITERATURE}

The relationships between emotional intelligence, leadership style and school culture was explored in this study. A review of the literature was conducted to provide a definition for each construct. A historical perspective of the development of each construct, the current diverse perspectives espoused by researchers regarding each construct, and the extant empirical evidence regarding the relationships among these variables is provided in the following sections.

\section{Emotional Intelligence}

Scholarly debate abounds in the literature. Differing perspectives regarding theories presented or constructs studied through empirical research are commonplace. Emotional intelligence is no exception, and varying conceptualizations of this construct have been posited (Bar-On, 1997; Goleman, 1995; Mayer Salovey \& Caruso, 2008; Petrides \& Furnham, 2001; and Van Rooy \& Viswesvaran, 2007). The term was first coined by Salovey and Mayer in 1990 (Salovey \& Mayer, 1990). Their work was rooted in the theories of social intelligence first described as early as 1920 (Thorndike, 1920), and in the subsequent theories of multiple intelligences developed by Gardner (1983). Salovey and Mayer have written extensively in defense of their definition of the construct as an intelligence based on ability, and have denounced the mixed model views of emotional intelligence developed by subsequent researchers (Mayer, Caruso, \& Salovey, 2000; Mayer \& Salovey, 1993; Mayer et al., 2008). A historical review of the development of the various theories and perspectives of emotional intelligence is crucial 
in understanding this fissure in the extant literature, the different definitions of the construct, and the distinctions in the assessment measures that have been developed.

The term emotional intelligence was first used and defined by Salovey and Mayer (1990) as "the subset of social intelligence that involves the ability to monitor one's own and others' feelings and emotions, to discriminate among them and to use this information to guide one's thinking and actions" (p. 189). These authors credited Gardner's theories of multiple intelligences (Gardner, 1983), and E.L. Thorndike's earlier work on social intelligence (Thorndike, 1920) with providing the foundation for their thinking. Their definition was also aligned with the one provided by R.L. Thorndike (Thorndike \& Stein, 1937), E.L. Thorndike's son: “the ability to understand and manage people" (p. 275), but added an inward perspective of this concept to include the ability to understand and manage oneself.

The initial description and conceptualization of the construct provided by Salovey and Mayer (1990) evolved and was further developed by the authors into a four-branch model (Mayer et al., 2008). Basically, emotional intelligence was first described as consisting of three distinct abilities: the appraisal and expression of emotion, the regulation of emotion, and the utilization of emotion. The first two, the appraisal and expression of emotion and the regulation of emotion pertain to both one's own and others' emotions. Both verbal and non-verbal components are involved in the appraisal and expression of one's own emotions; while non-verbal perception and empathy are key elements of the appraisal of others' emotions.

Salovey and Mayer (1990) perceived the appraisal and expression of emotion to be an essential aspect of emotional intelligence because individuals cannot respond 
appropriately to feelings without a clear understanding of those feelings; and, such appropriate responses are required for adequate social functioning. Similarly, regulation of emotions was included as an aspect of emotional intelligence because the authors indicated that this ability leads to more adaptive and reinforcing dispositions.

The third ability included in Salovey and Mayer's (1990) initial conceptualization of emotional intelligence, the utilization of emotion, referred to one's ability to regulate emotions to successfully adapt and solve problems. According to the authors, adaptation and problem solving skills require flexible planning, creative thinking, mood redirected attention, and motivation. Each of these abilities can be impacted by emotions or mood swings. That is, overarching positive moods can enhance one's ability to generate a diverse variety of future plans and ideas. By the same token, strong, unregulated emotions or moods can redirect one's attention from the problem or task at hand to a new, emotionally charged situation. Additionally, moods and emotions can effectively be employed to motivate persistence at challenging tasks (Salovey \& Mayer, 1990). Figure 1 depicts a graphic representation of this initial conceptualization of emotional intelligence.

Salovey and Mayer's work garnered criticism almost instantly as evidenced by the fact that they seemed compelled to defend their theory shortly after its initial introduction (Mayer \& Salovey, 1993). The initial criticism questioned the premise of defining awareness and behaviors based on emotions as an intelligence. The authors originating the concept responded with a rationale and defense for its classification as an intelligence, and further developed the construct into a four branch model of emotional abilities within a continuum ranging from lower level to higher level and more 
developmentally complex psychological functions (Mayer et al., 2000; Mayer \& Salovey, 1993; and Mayer et al., 2008).

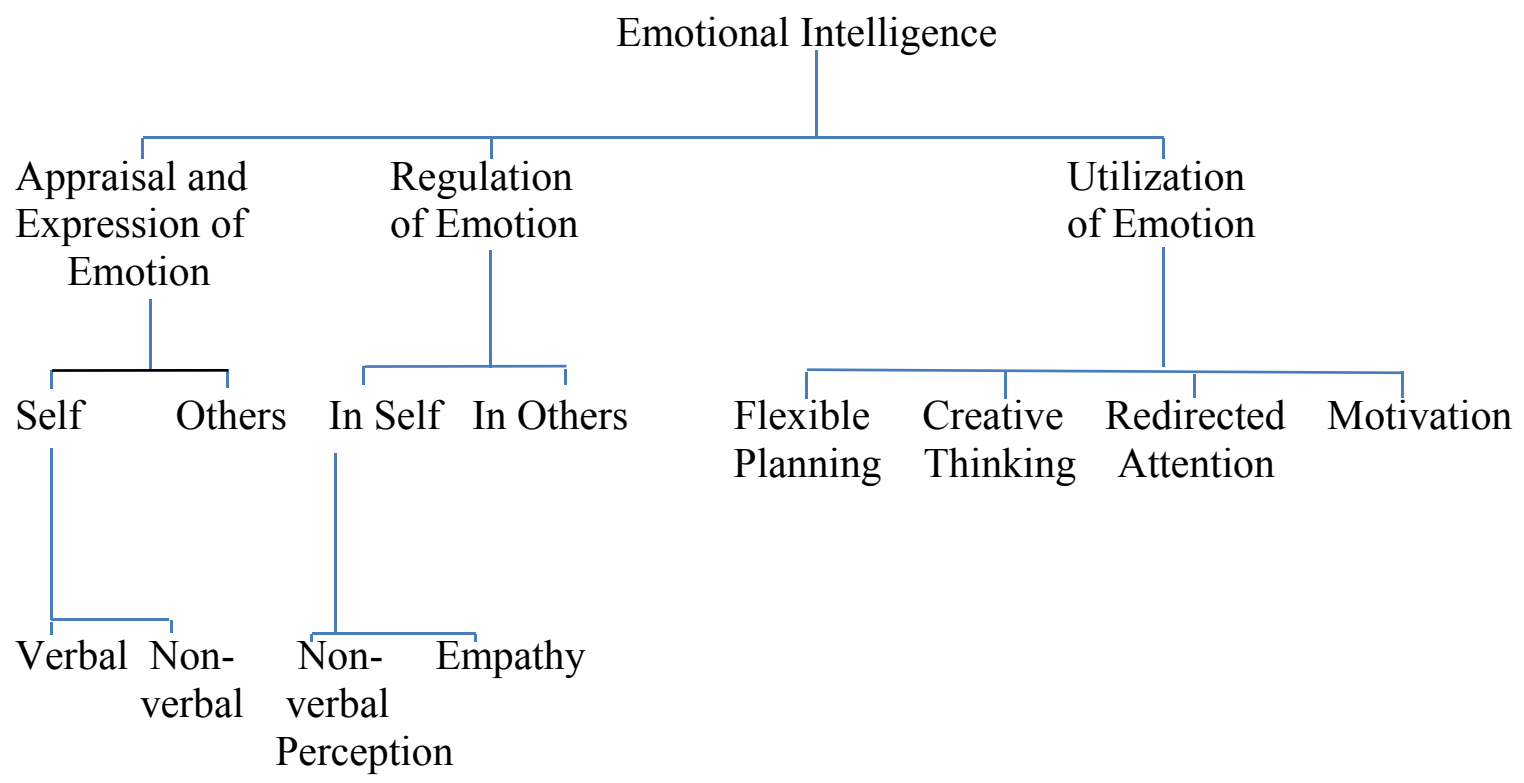

Figure 1. Conceptualization of emotional intelligence. From Salovey, P., \& Mayer, J.D. (1990). Emotional intelligence. Imagination, Cognition and Personality, 9(3), 185-211.

Salovey and Mayer (1993) argued that the construct is more appropriately viewed as an intelligence rather than a set of personality traits because the latter are dispositions toward behaviors, while intelligence involves abilities to behave or control behavior. Furthermore, knowledge of others' feelings is a mental ability, or a form of intelligence. These researchers provided empirical evidence to support their position in a study of the Multifactor Emotional Intelligence Scale (Mayer et al., 2000) which demonstrated that emotional intelligence as measured by this instrument met the three classical criteria of a standard intelligence. First, emotional intelligence was operationalized as a set of abilities. Second, the abilities defined by emotional intelligence were shown to be 
intercorrelated while also demonstrating unique variance and, finally, the abilities develop with age and experience. The four branch model of emotional intelligence subsequently developed by Mayer and Salovey (1997) steadfastly maintains the premise that the construct is an intelligence, and is juxtaposed with models and interpretations of the construct developed by other authors which include a mix of traits (Mayer et al., 2008).

The four branches, or sets of abilities involved in this revised conceptualization are arranged hierarchically from lower to higher levels of psychological functions. First, at the lowest level, emotional intelligence involves the ability to perceive emotions accurately in oneself and others. The next level involves the ability to use emotions to facilitate thinking. The third level includes the ability to understand emotions, emotional language, and the signals conveyed by emotions. And, finally, at the highest level of psychological functioning, emotional intelligence involves managing emotions to attain specific goals. In this revised four branch model, each branch consists of a set of skills evolving from easy or basic abilities to more complex, sophisticated ones. This refined conceptualization yields Salovey and Mayer's revised definition of ability-based emotional intelligence as the ability to perceive emotions, use emotions to facilitate thought, understand emotion, and regulate emotions to achieve goals (Mayer \& Salovey, 1997).

While Salovey and Mayer consistently adhered to their ability-based definition of emotional intelligence, differing perspectives of the construct quickly emerged in the literature, particularly in the aftermath of Goleman's (1995) best-selling book entitled Emotional Intelligence. Although this much publicized book popularized the concept, 
the author's magnified claims regarding the importance of emotional intelligence in terms of job performance and leadership ability were not substantiated by empirical research (Mayer et al., 2008). Moreover, the researchers who originally coined the term considered Goleman's rendition to be a journalistic perspective of the concept that incorporated other personality traits and diverted from the original theory they espoused, and attributed this publication with contributing toward the emergence of models and theories of emotional intelligence as a mix of traits not aligned with their original conceptualization of the construct (Mayer et al., 2008).

The first of these trait-based conceptualizations to emerge was introduced by Reuven Bar-On, who defined emotional intelligence as "an array of noncognitive capabilities, competencies, and skills that influence one's ability to succeed in coping with environmental demands and pressures" (Bar-On, 1997, p. 14). Bar-On's model of emotional intelligence involved a multifactorial array categorized into five areas: interpersonal skill, intrapersonal skills, adaptability, stress management, and general moods. Each of these five areas is sub-divided into components defined by the author. These components comprise the traits measured by the Bar-On Emotional Quotient Inventory (EQ-i), the self-report survey developed by the author to provide a measure of emotional intelligence (Bar-On, 1997). Bar-On's multifactorial array is depicted in Figure 2. Salovey and Mayer's criticism of this model involved its inclusion of attributes such as reality testing, assertiveness, self-regard and self-actualization which they consider to be unrelated to emotion, and which led them to consider such perceptions of emotional intelligence as mixed models (Mayer et al., 2008). Nonetheless, the Bar-On EQ-i, which measures emotional intelligence based on this multifactorial array, is the 
most widely used measure of emotional intelligence in empirical research (Van Rooy \&

Viswesvaran, 2007).

\begin{tabular}{|c|c|c|}
\hline $\begin{array}{l}\text { Component } \\
\text { Measured by } \\
\text { EQ-I Subscales }\end{array}$ & Definition & Area \\
\hline Self-Regard & $\begin{array}{l}\text { The ability to respect and accept oneself as basically } \\
\text { good. }\end{array}$ & \multirow{5}{*}{ 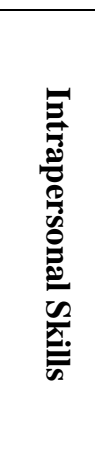 } \\
\hline $\begin{array}{l}\text { Emotional Self- } \\
\text { Awareness }\end{array}$ & The ability to recognize one's feelings. & \\
\hline Assertiveness & $\begin{array}{l}\text { The ability to express feelings, beliefs and thoughts and } \\
\text { defend one's rights in a nondestructive manner. }\end{array}$ & \\
\hline Independence & $\begin{array}{c}\text { The ability to be self-directed and self-controlled in one's } \\
\text { thinking and actions and to be free of emotional } \\
\text { dependency. }\end{array}$ & \\
\hline $\begin{array}{c}\text { Self- } \\
\text { Actualization } \\
\end{array}$ & The ability to realize one's potential capacities. & \\
\hline Empathy & $\begin{array}{l}\text { The ability to be aware of, to understand and to } \\
\text { appreciate the feelings of others. }\end{array}$ & \multirow{3}{*}{ 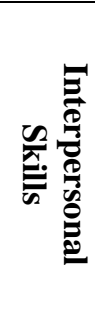 } \\
\hline $\begin{array}{c}\text { Social } \\
\text { Responsibility }\end{array}$ & $\begin{array}{l}\text { The ability to demonstrate oneself as a cooperative, } \\
\text { contributing and constructive member of one's social } \\
\text { group. }\end{array}$ & \\
\hline $\begin{array}{l}\text { Interpersonal } \\
\text { Relationship }\end{array}$ & $\begin{array}{l}\text { The ability to establish and maintain mutually satisfying } \\
\text { relationships that are characterized by intimacy and by } \\
\text { giving and receiving affection. }\end{array}$ & \\
\hline Reality Testing & $\begin{array}{l}\text { The ability to assess the correspondence between what is } \\
\text { experienced and what objectively exists. }\end{array}$ & \multirow{3}{*}{ 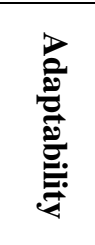 } \\
\hline Flexibility & $\begin{array}{l}\text { The ability to adjust one's emotions, thoughts and } \\
\text { behavior to changing situations and conditions. }\end{array}$ & \\
\hline $\begin{array}{l}\text { Problem } \\
\text { Solving }\end{array}$ & $\begin{array}{l}\text { The abilty to identify and define problems as well as to } \\
\text { generate and implement potentially effective solutions. }\end{array}$ & \\
\hline Stress Tolerance & $\begin{array}{l}\text { The ability to withstand adverse events and stressful } \\
\text { situations without "falling apart" by actively and } \\
\text { positively coping with stress. }\end{array}$ & \multirow{2}{*}{ 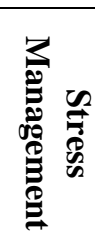 } \\
\hline Impulse Control & $\begin{array}{c}\text { The ability to resist or delay an impulse, drive or } \\
\text { temptation to act. }\end{array}$ & \\
\hline Optimism & $\begin{array}{l}\text { The ability to look at the brighter side of life and to } \\
\text { maintain a positive attitude, even in the face of adversity. }\end{array}$ & \multirow{2}{*}{ 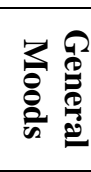 } \\
\hline Happiness & $\begin{array}{l}\text { The ability to feel satisfied with one's life, to enjoy } \\
\text { oneself and others and to have fun. }\end{array}$ & \\
\hline
\end{tabular}

Figure 2. Bar-On's Model of Emotional Intelligence. From Butler, C.J. and Chinowsky, P.S. (2006). Emotional intelligence and leadership behavior in construction executives. Journal of Management in Engineering, 22, 119-125. 
Goleman, credited with establishing the popularity of the construct and placing it in the forefront of research and scholarly work, also defined emotional intelligence in a manner Salovey and Mayer consider a mixed model by incorporating non-emotion related qualities such as trustworthiness, adaptability, innovation, communication, and team capabilities (Goleman, 1998b; Mayer et al., 2008). Other researchers have contributed to the discourse with a broader perspective of the construct than the one originated by Salovey and Mayer (Nelson \& Low, 2007; Petrides \& Furnham, 2001). Central to the existing rift in the literature, then, is the breadth with which the construct is conceptualized.

Contrasting Salovey and Mayer's view of the mixed model perceptions of emotional intelligence as "confusing" and too broad (Mayer et al., 2008), Petrides and Furnham (2003) found the Mayer-Salovey conceptualization of emotional intelligence to be too narrow. They provided a definition of the broader conceptualization of emotional intelligence, which they called trait EI: "Trait EI refers to a constellation of emotionrelated self-perceptions and dispositions, assessed through self-report” (p. 40). These authors recognized that the exact composition of these self-perceptions vary with the differing conceptualizations present in the literature.

They conducted a content analysis of the existing models of emotional intelligence provided by Bar-On (1997), Goleman (1995), and Salovey and Mayer (1990), and identified a sampling domain of trait EI (Petrides \& Furnham, 2001). This sampling domain consisted of adaptability, assertiveness, emotion appraisal, emotion expression, emotion management, emotion regulation, impulsiveness, relationship skills, 
self-esteem, self-motivation, social competence, stress management, trait empathy, trait happiness, and trait optimism (Petrides \& Furnham, 2001).

The crux of the matter is that the theoretical foundations of emotional intelligence overlap, regardless of whether the construct is conceptualized strictly as an ability-based intelligence or as an array of traits and attributes (Petrides \& Furnham, 2003). The concept of emotional intelligence is grounded in the theories of social intelligence and multiple intelligences (Gardner, 1983; Thorndike, 1920; Thorndike \& Stein, 1937). The distinction between the conceptualization of the construct as either ability-based or traitbased, however, is significant in conducting empirical research because various measurement methods have been developed, and research results are impacted by the manner in which the construct is conceptualized and operationalized (Petrides \& Furnham, 2003; Van Rooy \& Viswesvaran, 2007).

The Mayer Salovey Caruso Emotional Intelligence Test (MSCEITT), a revision of its precursor, the Multi-factor Emotional Intelligence Scale (MEIS) is the only instrument that has been developed to measure ability-based EI. This measure consists of a performance-based response format wherein the selection of the "correct" response is determined by the percent of respondents selecting each option. All other measurements are based on the conceptualization of the construct as trait EI, and rely on self-report measures that include personality aspects and cognitive abilities as well as emotionrelated skills (Van Rooy \& Viswesvaran, 2007). These measures include the Bar-On EQi, the Emotional Intelligence Scale (EIS), the Emotional Competency Inventory (ECI), the Emotional Judgment Inventory (EJI), and the Wong and Law Emotional Intelligence Scale (WLEIS). The manner in which the construct is conceptualized affects how it is 
measured because operationalization of the construct through self-response surveys will not yield the same results as operationalization through a performance test (Van Rooy \& Viswesvaran, 2007).

Thus, although two distinct conceptualizations of emotional intelligence emerged in the literature, both developed from a shared theoretical framework (Petrides \& Furnham, 2003). Clarification and distinction between ability-based EI and trait EI is essential in empirical research because how the construct is defined should be aligned with which measure is used, as well as with the hypotheses that are advanced and tested (Van Rooy \& Viswesvaran, 2007).

\section{Transformational Leadership}

Just as a debate exists in the literature regarding the emotional intelligence construct, disagreement regarding the qualities and characteristics of transformational leaders can also be found. This dispute, however, has been resolved by empirical research supporting the premise that transformational leadership is comprised of both transactional and transformational elements (Bass \& Avolio, 1994; Hallinger, 2003). The transformational leadership construct was introduced by James McGregor Burns (1978) in his seminal book entitled Leadership. He indicated that the "result of transforming leadership is a relationship of mutual stimulation and elevation that converts followers into leaders and may convert leaders into moral agents" (p. 4). Burns' work revolutionized views on leadership theory, and sparked a debate regarding the concepts of transformational leadership versus transactional leadership. Citing the hierarchies developed by Maslow and Kohlberg, Burns identified esteem, competency, selffulfillment and self-actualization as the higher-level needs of followers on which leaders 
should focus. By doing so, leaders possess the capacity to change, or transform, the nature of their followers; but, moreover, according to Burns, leaders have a moral commitment to do so.

Burns contrasted transformational leadership behavior with transactional leadership, in which the focus is on the lower-level needs described by Maslow. Traditional leadership, Burns believed, was transactional in nature. That is, leadership consisted of a series of exchanges between leaders and followers. Leaders provided money, benefits, recognition and other rewards in exchange for the desired behavior of the followers. Burns believed that leaders employ either transactional or transformational strategies, and advocated for the implementation of a transformational leadership style.

Bass and Avolio (1994) expanded on this discussion and argued that transformational leaders employ both transactional and transformational techniques. They elaborated on Burns' work and identified specific characteristics of transactional and transformational types of leadership. Transactional leadership includes both passive and active elements. Active transactional leadership techniques include contingent reward and management-by-exception. That is, rewards and recognition are contingent upon followers meeting stated objectives, and disciplinary techniques are employed when objectives are not met. Passive-avoidant or laissez-faire leadership practices are characteristic of leaders who fail to take action even when problems arise, and do not provide clear goals or expectations. Bass and Avolio (1994) felt that the active transactional leadership elements of contingent reward and management-by-exception are employed by leaders who also utilize transformational leadership strategies. 
Bass and Avolio (1994) elaborated on transformational leadership theory by delineating specific approaches attributed to transformational leaders. These include idealized influence, inspirational motivation, intellectual stimulation and individualized consideration. According to Bass and Avolio (1994), transformational leaders exercise idealized influence over their followers. They become role models. They earn the respect and admiration of their followers by placing their followers' needs above their own, and by behaving in a manner that is consistent with the goals and values of the group. Inspirational and intellectual stimulation is provided by transformational leaders who are enthusiastic, optimistic and generate "espirit de corps" among their followers, while encouraging innovation, creativity and input from followers. Finally, transformational leaders demonstrate individualized consideration for their followers when they act as coaches or mentors and foster their personal development. According to Bass and Avolio, transformational leaders utilize these strategies in conjunction with the active elements of transactional leadership of contingent reward and management-byexception.

Although transformational leadership was introduced as early as 1978, the prevailing leadership style in schools during this era was instructional leadership. Transformational leadership theory did not emerge in the context of school leadership until the 1990s (Hallinger, 2003; Leithwood, 1994). Since its emergence in this setting, however, transformational leadership in schools has been strongly supported in the literature (Barth, 2002; Fullan, 2002; Hallinger, 2003; Leithwood, 1992, 1994).

Hallinger (2003) provided a perspective on the distinction between instructional leadership and transformational leadership. The basic difference concerns a leadership 
approach that involves "second order" change as opposed to "first order" change (Leithwood, 1994). Instructional leadership models emerged in the 1980s against the backdrop of the overwhelming calls for school reform propelled by the publication of $A$ Nation at Risk in 1983 and within the context of research on effective schools. During this era, a rapid, effective reaction was expected of school leaders in implementing change and directly impacting student achievement (Hallinger, 2003). Principals were expected to take charge, to become directly involved with teachers, curriculum and the instructional program, and effectively manage the people within the organization. Instructional leadership involved "first order" change, and implemented a top-down approach to school improvement and to the power relationships within the schools (Hallinger, 2003; Leithwood, 1994).

In the 1990s, however, a different perspective emerged. Although principal leadership was still considered to be the single most critical factor in ensuring school effectiveness, the complex nature of this role was recognized (Cistone \& Stevenson, 2000). The principal was no longer viewed as the center of power and authority. Rather, the concepts of shared leadership and distributive leadership in school settings took hold (Harris, 2004; Henkin, Cistone \& Dee, 2000; Sergiovanni, 2004). Researchers recognized that principals indirectly affect school improvement by impacting the organization and the people within it (Leithwood, 1994; Hallinger, 2003; Witziers et al., 2003). This leadership approach involved "second order" change, in which leaders impacted organizational outcomes through their influence on the people within the organization and the organization itself (Leithwood, 1994), and was aligned with transformational leadership theory (Bass \& Avolio, 1994; Burns, 1978; Hallinger, 2003). 
Transformational leadership in school settings has been found to impact teachers' perceptions of school conditions, their commitment to change, the organizational learning that occurs, and "focuses on developing the organization's capacity to innovate" (Hallinger, 2003, p. 330). The transformative power of this leadership style is the result of its effect on the people being led, or the followers, and requires a change in the power relationships between the leader and the followers (Fullan, 2002; Leithwood, 1992). Fullan (2002) identified five essential components of leadership that can transform followers, which are aligned with Burns' (1978) initial description of transformational leadership. First, leaders must possess a moral purpose, a sense of moral responsibility to others and to the organization toward developing other leaders in the school. Secondly, leaders must understand the change process, to include an understanding of the inevitable roadblocks and resistance efforts that emerge within the context of change, and must understand how to handle and address these issues in order to move forward. Third, leaders that can transform followers must focus on improving their relationships with followers, which requires enhanced emotional intelligence (Fullan, 2002). Finally, principals that can transform followers must create an environment in which knowledge is openly shared, and must bring cohesiveness and unity to the complex and fragmented nature of school environments.

Leithwood (1992) also stressed the importance of leader-follower relationships in transformational leadership, and indicated that school reform hinges on a change in the power relationships and a move toward distributed leadership. Such an approach requires a balance between the top-down and bottom-up use of power, and would increase the problem solving capacity of all members of the organization. Consequently, in 
accordance with Bass and Avolio (1994), Leithwood (1992) viewed transactional and transformational leadership practices as complementary because transactional practices are associated with a top-down use of power, while transformational practices are associated with a bottom-up use of power, and a balance between the two is recommended. Rather than focusing on a distinction between "first order" and "second order" change, Leithwood (1992) posited that these concepts are more complexly intertwined in that significant "second order" change is a prerequisite to achieving "first order" change.

Leithwood (1994) supported transformational leadership as the appropriate style for school restructuring, particularly as contrasted with instructional leadership, arguing that the means and ends for school restructuring are not certain. When these are clear, a top-down instructional leadership approach can be effective. However, when they are not, a bottom-up transformational style is more appropriate. Transformational leadership is also more appropriate in effecting both "first order" and "second order" change, both of which are necessary for school restructuring; and, transformational leadership is the most appropriate style in a move toward the professionalization of teaching, which is also at the core of school restructuring.

Leithwood (1994) cited his own empirical research in school settings which was based on interrelated constructs with a causal relationship as additional evidence for his argument. This framework involves the transformational leadership variable as affecting the psychological dispositions of teachers' perceptions of school characteristics, teacher commitment to change, and organizational learning. These psychological dispositions in turn affected the outcomes of restructuring initiatives and student achievement. Utilizing 
the path analysis provided by this framework, Leithwood (1994) found vision building and fostering commitment to goals to be the transformational leadership practices most strongly associated with the outcomes studied. Additionally, he concluded that individualized consideration was the most influential dimension of transformational leadership in school settings. Thus, although debate can be found in the literature regarding the dimensions included in transformational leadership, particularly regarding whether or not transactional leadership strategies should be utilized by transformational leaders, for the most part, the debate has been resolved (Hallinger, 2003). Most scholars acknowledge that transformational leaders do, at times, employ transactional approaches, and that transformational leadership is the most appropriate and effective approach to school leadership (Barth, 2002; Fullan, 2002; Hallinger, 2003; Leithwood, 1992, 1994). Leithwood's (1994) framework also acknowledges that out of school conditions affect teachers' psychological dispositions, and ultimately, the outcomes of school reform efforts. This insight is especially relevant within the current atmosphere where increasing legislative demands on schools present a challenge for principals who find their roles diminished by these outside sources (Conley, 2003). Adopting an appropriate leadership style in this context is vital, and school leaders must temper their efforts with an understanding of the emotional impact that initiating change and instituting reform may have on teachers (Reio, 2005). Thus, both transformational leadership strategies and principals' emotional intelligence are relevant (Goleman, 1995a; Fullan, 2002;

Leithwood, 1994). 


\section{Transformational Leadership and Emotional Intelligence}

A pressing question among scholars of leadership theory concerns the relationship between transformational leadership and emotional intelligence (Antonakis, 2003; Brown \& Moshavi, 2005; Fullan, 2002; Prati, et al., 2003). Empirical research conducted in various contexts exploring this relationship has been inconclusive, yielding both statistically significant relational findings, and no significant findings (Barbuto \& Burbach, 2006; Butler \& Chinowsky, 2006; Duckett \& Macfarlane, 2003; Leban \& Zulauf, 2004; Weinberger, 2009). Common ground among these researchers can be found in their recommendation that additional research regarding these relationships is necessary to advance the development of leadership theory, which was one of the major goals of the present study.

Brown and Moshavi (2005) attributed the discrepancy of the empirical research findings on the varying definitions of emotional intelligence that have evolved, and on the various measures of the construct that have been developed. These authors concurred that further study is warranted due to the potential research and practical value of substantiating such a relationship. Interestingly enough, disputes among scholars exist even in preparing the foundation for such research (Antonakis, 2003; and Prati, et al., 2003). Prati (2003) and colleagues developed a conceptual model incorporating existing theory and research regarding emotional intelligence and leadership, concluded that emotional intelligence is a critically important aspect of effective leadership, and presented various propositions for future research. Antonakis (2003), on the other hand, provided a succinct commentary that was diametrically opposed to these authors' 
perspective, and posited that engaging in empirical research in search of support for such a relationship is premature at best.

These arguments emerged against the backdrop of extant empirical research which produces support for both perspectives. Studies conducted in diverse settings - the corporate world, construction, and retail sales - utilizing different measures of the construct, revealed a significant relationship between emotional intelligence and transformational leadership (Barling, Slater \& Kelloway, 2000; Butler \& Chinowsky, 2006; Duckett \& Macfarlane, 2003; Leban \& Zulauf, 2004). Specifically, measures of trait emotional intelligence using the EQ-i and ability emotional intelligence using the MSEIT were found to be positively related to three aspects of transformational leadership as measured by the MLQ 5X -idealized influence, inspirational motivation and individualized consideration. Negative relationships between the laissez-faire and management-by-exceptions aspects of transactional leadership and emotional intelligence were also substantiated (Barling, Slater \& Kelloway, 2000; and Leban \& Zulauf, 2004). Similar correlational studies did not mirror these findings (Barbuto \& Burbach, 2006; and Weinberger, 2009). Barbuto and Burbach (2006) did find a modest relationship between trait emotional intelligence and transformational leadership. However, their results did not provide sufficient support for the predictive value of emotional intelligence as an antecedent of leadership style. Additional findings supported Lindebaum and Cartwright's (2010) caveat regarding common method bias because a stronger relationship between emotional intelligence and transformational leadership was found when comparing leaders' self-report versus rater-report responses measuring transformational leadership behaviors (Barbuto \& Burbach, 2006). 
Weinberger's (2009) study of managers in a manufacturing organization utilizing the MSEIT and the MLQ 5X to explore the relationship between ability emotional intelligence and transformational leadership yielded no statistically significant relationship between the two constructs.

Given these disparate findings in the literature, Harms and Credé (2010) conducted a meta-analysis in an attempt to establish whether or not, and under what circumstances, a relationship between transformational leadership and emotional intelligence can be supported. Confirming the concerns regarding common source bias expressed by others (Barbuto \& Burbach, 2006; Lindebaum \& Cartwright, 2010), these authors reported stronger relationships between emotional intelligence and transformational leadership were found when the raters were the same as compared with findings of studies in which raters were different. In terms of transactional components of leadership, contingent reward was found to be positively related to emotional intelligence, while management-by-exception (passive) and laissez-faire components were negatively related to emotional intelligence. Additionally, trait measures of emotional intelligence were more strongly related to transformational leadership than ability based measures in instances of both same-source and multisource ratings. The authors concluded that although some of the extreme claims regarding the significant role of emotional intelligence in determining leadership style could not be established, their meta-analysis did not rule out the possibility that emotional intelligence could play an important role in leadership theory, and joined others in calling for additional research (Barbuto \& Burbach, 2006; Fullan, 2002; Harms and Credé, 2010; Nelson et al., 2007, Weinberger, 2009). 
The relationship between emotional intelligence and transformational leadership style may be either that of emotional intelligence as an antecedent of transformational leadership or possibly as having an interactive or additive effect on transformational leadership (Brown \& Moshavi, 2005). Fullan's (2002) view that employing a transformational leadership style requires improving relationships between the leader and his followers, which is contingent upon the leader's enhanced emotional intelligence, suggested that emotional intelligence would be an antecedent to transformational leadership behaviors. Establishing support for a relationship between emotional intelligence and transformational leadership style is significant in the study of leadership theory because emotional intelligence has been defined as a learned skill that can be developed (Nelson et al., 2007). Nelson and his colleagues adopt a trait-based perspective of emotional intelligence, delineated specific skills associated with the construct which can be learned and developed, and provided a method of assessing the development of these skills (Nelson et al., 2007).

Ultimately, however, within the context of school leadership, the focus must return to school effectiveness and student achievement. As Witziers et al. (2003) revealed, a principal's leadership style has an indirect effect on student achievement by impacting the school's culture. The question for scholars of leadership theory then becomes whether leaders who employ transformational leadership strategies are successful in transforming their followers, and thereby the culture of their organization. Addressing this question requires a closer look at research regarding the principal's role within the context of school culture, and the impact of transformational leadership behaviors on school culture. 


\section{Principals, Transformational Leadership and School Culture}

Culture has been defined as "the underground stream of norms, values, beliefs, traditions, and rituals that has built up over time" (Peterson \& Deal, 1998, p. 28). Schein (1985) suggested that these common views operate at a deep, almost subconscious level. The key to building a positive culture is to first read and understand the existing culture, articulate values, and foster positive values while modifying negative values (Peterson \& Deal, 1998). Some researchers offered thoughts on strategies for building a positive school culture, stressing the importance of rituals and ceremony (Rud \& Garrison, 2010), and of celebrating accomplishments (Davies \& Brighouse, 2010). The relationship between principals and school culture has been considered to be a reciprocal one (Barth, 2002; Hallinger, 2003; Witziers et al., 2003). That is, "leaders not only shape cultures, but adapt to them" (Witziers et al., 2003, p. 416)—a concept aligned with Burns' (1978) view regarding transformational leaders. In his conceptualization of transformational leadership, an almost symbiotic relationship is developed between leaders and followers in which both are transformed and elevated to higher levels of moral sensitivity (Burns, 1978).

Building a positive school culture has been considered to be inextricably intertwined with the people who inhabit the school. Positive relationships between the principal and school staff have been deemed vital (Fullan, 2002). The human resources frame described by Bolman and Deal (2008) plays a pivotal role in effective leadership practices for shaping a positive school culture. Rud and Garrison (2010) and Lumpkin (2008) addressed the importance of empowering people and collaboration. Rud and Garrison indicated that effective leaders distribute and share leadership. Lumpkin 
identified building relationships through delegating without micromanaging and the synergy of teamwork as the keys of successful leadership. Davies and Brighouse (2010) stressed that leading with reverence requires that leaders demonstrate they care for those being led.

Shared leadership has been an essential component of building school cultures (Harris, 2004; Marks \& Printy, 2003; Sergiovanni, 2004). Harris (2004) reviewed two empirical studies of distributed leadership and school improvement, and acknowledged that although effective leaders have a powerful influence on schools, this influence is indirect. In exploring the question of the type of leadership that positively affects student achievement, Harris stressed the importance of building capacity within school staffs. This is accomplished by distributing leadership. In the two studies she reviewed, the leaders involved were diverse in age, level of experience, stages of career and working environment. However, they shared a common approach to leadership, implementing distributed leadership practices that empowered others to lead. These practices, Harris found, led to increased self-esteem and self-efficacy among their staffs. She points to "an emerging model of leadership that is less concerned with individual capabilities, skills and talents and more preoccupied with creating collective responsibility for leadership action and activity" (p. 19). These views, again, are aligned with Burns' (1978) vision of what transformational leaders accomplish.

Sergiovanni (2004) would applaud this approach because it serves to build organizational competence, which is dependent on the collective intelligence of all individuals within the organization. He explored shared leadership in practice at a particular school "committed to building the leadership capacity" of the staff, and in 
"dispersing leadership throughout the organization" (p. 51). The organizational structure of this school was described as "less hierarchical and more flat" (p. 51), and the focus was on collaboration rather than line of authority. Sergiovanni stated: "By definition, leadership and norms go together. Thus, the effectiveness of leadership is measured by its effect on cultural norms" (p. 52). Cultural norms conducive to distributed leadership practices, would, according to Sergiovanni, enhance organizational competence by enhancing the collective intelligence of the organization.

Kelley, Thornton and Daugherty (2005) also emphasized the principals' impact on school culture or cultural norms, stating "Educational leadership is possibly the most important single determinant of an effective learning environment" (p. 17). Empowering teachers to share leadership is crucial to support teacher commitment to the organization (Marks \& Printy, 2003). Transformational leadership would be pivotal in building organizational competence because transformational leaders turn followers into leaders (Burns, 1978).

Saphier and King (1985) identified collegiality, experimentation, high expectations, trust and confidence, tangible support, reaching out to the knowledge bases, appreciation and recognition, caring, celebration and humor, involvement in decision making, protection of what's important, traditions, and open, honest communication as cultural norms vital to school improvement. These norms can be aligned with the practices attributed to transformational leaders delineated by Bass and Avolio (1994). Idealized influence and individualized consideration could be aligned with honest, open communication, protecting important traditions, caring, celebration and humor, and trust and confidence. Intellectual stimulation would foster experimentation, reaching out to 
the knowledge bases, and involving followers in making decisions. Inspirational motivation would affect collegiality, involve setting high expectations, providing tangible support, and appreciation and recognition.

The literature revealed agreement among scholars regarding a principal's vital role in developing and fostering a positive school culture (Barth, 2002; Hallinger, 2003; Maslowski, 2001; Peterson \& Deal, 1998; Saphier \& King, 1985; Witziers et al., 2003). Many of the qualities and characteristics attributed to principals who effectively build school culture are aligned with the elements of transformational leadership practices (Burns, 1978; Davies \& Brighouse, 2010; Fullan, 2002; Harris, 2004; Marks \& Printy, 2003; Rud \& Garrison, 2010; Sergiovanni, 2004). Transformational leadership has been attributed with fostering organizational learning in schools (Leithwood, Leonard \& Sharratt, 1998), and as leading to teacher job satisfaction (Bogler, 2001). Both organizational learning and job satisfaction have been identified as elements of a positive culture (Schein, 1996). However, Leithwood and Jantzi (2005) reviewed empirical studies of transformational leadership in school settings and revealed that these studies included school culture as a mediator and focused on student outcomes as the dependent variable. Because scholars have argued that principals impact student outcomes indirectly by influencing the school's culture, there is a need for additional research exploring the relationship between these variables in which school culture is the dependent variable - the purpose of the current study.

\section{Emotional Intelligence, Transformational Leadership and School Culture}

Many qualities attributed to effective leaders have been considered to be associated with leaders demonstrating emotional intelligence (Goleman, 1998), and 
employing a transformational leadership style (Burns, 1978). Goleman (1998a) argued that exhibiting emotional intelligence results in enhancing a leader's trustworthiness or integrity. Integrity has been identified as a key quality of successful leadership, with an emphasis on a need for leaders to model values and shape school culture (Lumpkin, 2008). Effective school leaders have also been described as passionate individuals who establish values and approach their commitment to school improvement with a moral foundation (Davies and Brighouse, 2010). Passion, an emotional aspect of leadership, propels principals to inspire with energy and commitment. Bolman and Deal (2002) included passion and integrity as qualities of effective principals, and Sergiovanni (2005) identified the four virtues of leadership as hope, trust, piety and civility.

Rud and Garrison (2010) explored the concept of reverence as it relates to school leadership, utilizing the capsule definition of reverence proposed by Woodruff (2001): "the capacity for a range of feelings and emotions that are linked. It is a sense that there is something larger than a human being, accompanied by capacities for awe, respect, and shame" (p. 63). Rud and Garrison (2010) perceived reverence as bringing unity to the virtues attributed to successful leaders. Reverence is the glue that holds all other virtues together and binds a school. Reverent leaders possess a sense of awe, wonder, and respect for others. Leaders who exhibit these qualities can successfully build and shape a positive culture within their schools. Moreover, these qualities have been linked to emotional intelligence and transformational leadership (Burns, 1978; Goleman, 1998). Theories of emotional intelligence, transactional and transformational leadership, and school culture provide the foundation for the conceptual framework that propelled the 
present study (Bass \& Avolio, 1994; Burns, 1978; Salovey \& Mayer, 1990; Schein, 1996). 


\section{CHAPTER III}

\section{METHOD}

The purpose of this study was to explore the relationship between principals' emotional intelligence, teachers' perceptions of principals' leadership styles and school culture in schools within a large urban school district in southeast Florida. Each variable was hypothesized to contribute unique variance to predicting school culture. The relationship between emotional intelligence and transformational leadership was explored to determine whether emotional intelligence can be considered to be an antecedent of transformational leadership. The interactive relationship between emotional intelligence and transformational leadership in predicting school culture was also explored. Figure 3 depicts the conceptual framework for this study. The research design, methodology and instrumentation that were employed are delineated in this chapter.

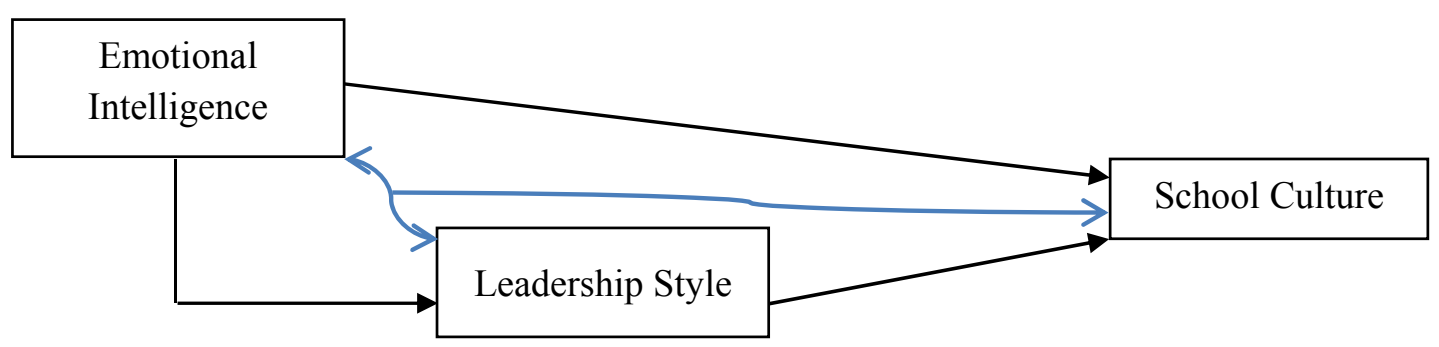

Figure 3. Conceptual model of the relationships between emotional intelligence, leadership style and school culture.

Note. The wavy lines depict the interactive relationship between emotional intelligence and transformational leadership in predicting school culture.

\section{Research Design}

The researcher implemented a non-experimental ex post facto research design to investigate specific research hypotheses developed through a review of prior research and 
theoretical frameworks presented in the literature. This design was appropriate given that the research questions were based on variables that are considered attributes and cannot be manipulated by the researcher (Newman \& Newman, 2005). The researcher attempted to support correlations that may enhance the knowledge base for current theoretical frameworks present in the literature.

Ex post facto designs are inherently weak in terms of internal validity. Of the three types of ex post facto research — without hypotheses, with hypotheses, and with hypotheses and tests of alternative explanations - the third was employed (Newman \& Newman, 2005). Because the study investigated previously stated hypothetical relationships, hypotheses were included in this research. A statistical hypothesis designed to eliminate alternative explanations was also included, thereby strengthening internal validity (Newman \& Newman, 2005). A non-experimental ex post facto research design was an effective choice for this study because it aided the researcher in identifying emotional intelligence as a variable related to the criterion variables of transformational leadership and school culture for use in future research. These relationships are pertinent to the research questions and hypotheses posited because prior research has indicated that emotional intelligence can be learned (Nelson \& Low, 2003).

In terms of external validity, generalizability was enhanced by several factors within the methodology employed. First, the schools involved in the study were randomly selected from all public elementary schools within three organizational regions located in a large urban school system in southern Florida. Second, the degree of generalizability may be subsequently enhanced by replication of the findings in other 
school settings, such as other school districts or schools at other educational levels (McNeil, Newman \& Fraas, 2012).

\section{General and Specific Research Hypotheses}

The ultimate goal of improved student achievement is of primary concern in the literature (Witziers et al., 2003). Additionally, there is much interest regarding the relationships between principals' emotional intelligence, principals' leadership style, and their schools' culture. Specifically, researchers have suggested that emotional intelligence could be an antecedent of transformational leadership (Brown \& Moshavi, 2005). To researchers, the relevance of these relationships stems from findings that support the concept that emotional intelligence is a learned ability (Nelson \& Low, 2003). Based on these findings in the literature, the following general research hypotheses and specific research hypotheses were developed to address each of the research questions:

Research Question 1. Does the emotional intelligence of public elementary school principals account for a significant amount of unique variance in predicting leadership style?

General Research Hypothesis 1. There is a relationship between the EQ-i scores of elementary school principals and their scores on the MLQ Form 5X.

Specific Research Hypothesis 1. The EQ-i scores of elementary school principals account for a significant amount of unique variance in predicting their scores on the MLQ Form 5X. 
In investigating the relationship between the principals' emotional intelligence, leadership style and school culture, the researcher first determined whether or not emotional intelligence and leadership style interact in predicting school culture. Consequently, the following general and specific research hypotheses were developed based on the second research question.

Research Question 2. Is there an interaction between the emotional intelligence of public elementary school principals and their leadership style in predicting school culture?

General Research Hypothesis 2. There is a relationship between the EQ-i scores of public elementary school principals, their scores on the MLQ Form 5X and school culture.

Specific Research Hypothesis 2. The interaction between the EQ-i scores of public elementary school principals and their scores on the MLQ Form 5X accounts for a significant amount of unique variance in predicting school culture over and above the additives.

Because significant interaction between emotional intelligence and leadership measures at the alpha level of .05 was not found when the full and restricted models for Specific Research Hypothesis 2 were tested, this hypothesis was rejected and the main effects of leadership style and emotional intelligence were explored (McNeil et al., 2012). The following research hypotheses were utilized to test for main effects based on the third and fourth research questions. 
Specific Research Hypothesis 3. The public elementary school principals' scores on the MLQ Form 5X account for a significant amount of unique variance in predicting school culture over and above their EQ-i scores.

Specific Research Hypothesis 4. The public elementary school principals' EQ-i scores account for a significant amount of unique variance in predicting school culture over and above their scores on the MLQ Form $5 \mathrm{X}$.

Finally, the following statistical hypothesis designed to eliminate an alternative explanation was developed (McNeil et al., 2012; Newman \& Newman, 2005).

Statistical Hypothesis. Over and above the influence of school grade, scores on the MLQ Form 5X account for a significant amount of unique variance in predicting school culture.

\section{Participants}

Fifty seven principals and 850 teachers from elementary schools within a large urban public school system in south Florida participated in this study. Specific demographic information regarding the principals and faculty members responding to the surveys is detailed in Table 1. The response rate for principals was 70.37 , with 57 of the 81 principals who agreed to participate responding. The response rate for teachers was 34.91 , with 850 teachers responding from the total of 2,435 surveys distributed. 
Table 1

Summary of Principal and Teacher Demographics

\begin{tabular}{|c|c|c|c|c|}
\hline \multirow{2}{*}{ Profile } & \multicolumn{2}{|c|}{ Profile of Principals } & \multicolumn{2}{|c|}{ Profile of Teachers } \\
\hline & $N$ & Percentage & $N$ & Percentage \\
\hline \multicolumn{5}{|l|}{ Sex } \\
\hline Male & 18 & 31.6 & 75 & 8.8 \\
\hline Female & 39 & 68.4 & 775 & 91.2 \\
\hline \multicolumn{5}{|l|}{ Age } \\
\hline $18-25$ & & & 10 & 1.2 \\
\hline $26-34$ & 2 & 3.5 & 132 & 15.5 \\
\hline $35-54$ & 37 & 64.9 & 521 & 61.4 \\
\hline $55-64$ & 18 & 31.6 & 165 & 19.4 \\
\hline 65 or older & & & 21 & 2.5 \\
\hline \multicolumn{5}{|l|}{ Race/Ethnicity } \\
\hline White & 15 & 26.3 & 183 & 21.6 \\
\hline African American & 8 & 14.0 & 78 & 9.2 \\
\hline Hispanic & 34 & 59.7 & 529 & 62.6 \\
\hline Asian & & & 5 & 0.6 \\
\hline Native American & & & 3 & 0.3 \\
\hline Other & & & 48 & 5.7 \\
\hline \multicolumn{5}{|l|}{ Education } \\
\hline Bachelor's Degree & & & 317 & 37.5 \\
\hline Master's Degree & 26 & 54.6 & 423 & 50.1 \\
\hline Specialist's Degree & 18 & 31.6 & 12 & 1.4 \\
\hline Doctorate Degree & 13 & 22.8 & 93 & 11.0 \\
\hline \multicolumn{5}{|l|}{ Years of Experience } \\
\hline $0-2$ & 6 & 10.5 & 24 & 2.9 \\
\hline $3-5$ & 10 & 17.5 & 37 & 4.4 \\
\hline $6-10$ & 25 & 43.9 & 174 & 20.8 \\
\hline 11 or more & 16 & 28.1 & 602 & 71.9 \\
\hline \multicolumn{5}{|l|}{ Years at Current } \\
\hline $0-2$ & 9 & 15.8 & 101 & 12.1 \\
\hline $3-5$ & 21 & 36.8 & 104 & 12.4 \\
\hline $6-10$ & 21 & 36.8 & 273 & 32.6 \\
\hline 11 or more & 6 & 10.5 & 360 & 42.9 \\
\hline
\end{tabular}




\section{Variables}

Because the primary purpose of this study was to examine relationships among the identified variables, statistical analyses were conducted in which most variables sometimes served as predictor variables and sometimes as criterion variables. Variables included emotional intelligence $(\mathrm{EI}=$ total standard score on the self-report EQ-i completed by principals), leadership style (LS $=$ the mean score on each of the dimensions of transformational leadership, transactional leadership and passive-avoidant behaviors measured by the MLQ Form $5 \mathrm{X}$ completed by teachers), and school culture $(\mathrm{SC}=$ the percent of strongly agree or agree responses on items in the School Climate Survey completed by teachers related to each of the identified subscales measuring two different facets of school culture).

\section{Sampling Procedures}

Miami-Dade County Public Schools, the school district in which this study was conducted, is the fourth largest school district in the United States and encompasses a large geographical area. For organizational purposes, Miami-Dade County Public Schools is divided into three geographic regions: North, Central and South. In order to obtain a representative sample from all regions within the district, a stratified random sampling technique was employed to select the 86 principals invited to participate in this study. Schools were divided into three sub-groups or strata based on the organizational structure within the district. There are a total of 146 elementary schools in the three regions, 48 in the Central Region (33\% of the 146 schools), 47 in the North Region (32\% of the 146 schools) and 51 in the South Region (35\% of the total 148 schools). Consequently, the corresponding percentage of schools from each of these strata was 
randomly selected for participation in the study using a computer random-number generator (Trochim \& Donnelly, 2008). A total of 86 principals were invited to participate. Four declined to participate, and one, who had been newly assigned to the school within the previous two weeks, was excluded from the study. Of the 81 principals who agreed to participate, 57 completed the survey.

\section{Instruments}

Three instruments were used to measure the variables in this study. Following are descriptions of each, along with a rationale for its selection as a measure of each variable.

\section{Bar-On Emotional Quotient Inventory (EQ-i)}

The EQ-I is a 133-item self-report survey using a 5-point Likert-type scale ranging from responses of "very seldom or not true of me" to "very often true of me". Scores are provided by the test publisher and normed by age group. Scores provided include a total score, as well as scores from four composite scales measuring intrapersonal EQ, interpersonal EQ, adaptability, and stress management. The total standard score EQ-i was used in this study. Standard scores are adjusted scores normed by age group and scaled with a mean score of 100 and a standard deviation of 15 . Reliability coefficients for the subscales of the EQ-i range from $\alpha=.69$ to .86 across 10 studies, while the alpha value for the total score was .97 (Bracket \& Mayer, 2003). This self-report survey was selected for use in this study as a strategy to minimize the effect of common method variance identified by Lindebaum and Cartwright (2010), because data regarding transformational leadership style was obtained through an instrument completed by teachers at each school. 


\section{The Multifactor Leadership Questionnaire (MLQ Form 5X)}

The revised Multifactor Leadership Questionnaire (MLQ) is a short 45-item survey measuring leadership dimensions that include transformational leadership styles, transactional leadership styles, and passive-avoidant behaviors, as well as outcomes of leadership, such as effectiveness (Bass \& Avolio, 1994). This survey has been used extensively in research and is considered a strong predictor of leader behavior (Lindebaum \& Cartwright, 2010). Alpha reliability coefficients for the MLQ Form 5X subscales yielded a range of .77 through .95 (Bass \& Avolio, 1990).

\section{The Miami-Dade County Public Schools School Climate Survey}

The Miami-Dade County Public Schools School Climate Survey was utilized as a data source for school culture. This instrument was selected because the results are easily accessible through the district's web site, and because it has been used previously by researchers (Horng, Klasik \& Loeb, 2010). The School Climate Survey consists of three forms with a set of statements requiring responses in a Likert-type scale format of strongly agree, agree, unknown/undecided, disagree or strongly disagree completed by the school's students, parents and staff. A different form is used for each of these populations. For the purposes of this study, only the results of the staff form were used for analysis. This form contains 34 statements, which were categorized by the researcher as either relating to teacher professionalism and goal setting or professional treatment by administration to align with two subscales of the School Culture Survey (Saphier \& King, 1985; Edwards et al., 1996). The district's web site provides information regarding the reliability of this survey. The total reliability estimate reported by the school district for the staff form is an alpha of 0.88 . 


\section{Data Collection}

Data collection began upon approval from both the Institutional Review of Board Research Compliance of Florida International University and the Miami-Dade County Public Schools Research Review Committee. The researcher personally contacted each principal of the schools randomly selected for participation in the study via telephone, explained the purpose of the study, and invited the principals to participate. The researcher asked principals who agreed to participate to also assist the researcher by asking their teachers to complete the teacher surveys.

Online surveys utilizing Qualtrics Survey Software were constructed by the researcher. Surveys consisted of two parts. The first part included items requesting demographic information. The second part of the online survey distributed to principals included all the survey items and response options found on the traditional pencil and paper version of the EQ-i. The second part of the online survey distributed to teachers included all the survey items and response options found on the traditional pencil and paper version of the MLQ Form 5X.

Electronic communications via the school district's e-mail containing a brief explanation of the study, assurance of anonymity and a link to the survey were sent to the principals who agreed to participate. An informational letter regarding the study (Appendix A) and the approval letter to conduct research from the Miami-Dade County Public Schools Research Review Committee were attached to this e-mail correspondence. The principals' responses to the EQ-i were compiled by the researcher, coded with a number to match the responses from the teachers at their schools, and submitted to the 
test publisher for scoring. Scored response sets were imported into a Statistical Package for the Social Sciences (SPSS) file for analysis.

Once principals' responses were received, the researcher sent electronic communications to all teachers at each principal's school. The invitations for participation to teachers also included a brief explanation of the study, assurance of anonymity and a link to the survey. An informational letter regarding the study (Appendix A) and the approval letter to conduct research from the Miami-Dade County Public Schools Research Review Committee were attached to this e-mail correspondence as well. Follow-up e-mails were then sent to principals thanking them for their participation, advising them that the survey links had been e-mailed to their faculty members, and asking their assistance in encouraging their teachers to participate. Teachers' survey responses were maintained on the password protected Qualtrics Survey Software server, and imported into an SPSS file for analysis. No identifying information for teachers was obtained, and schools were coded with a number. All data stored on the Qualtrics server will be removed 1 year after completion of this study.

Survey data were collected from February 2014 through March 2014. Strategies were implemented to control for non-response rate (Rogelberg \& Luong, 1998). Three follow-up reminder e-mails were sent to non-responding participants-both principals and faculty members - within 5-7 day intervals of the original invitation to participate, and within 5-7 day intervals of the previous reminders. Principals were sent copies of the reminders sent to their teachers and asked once again to assist by encouraging teacher participation. Utilizing these strategies, a response rate of $70.37 \%$ was achieved for 
principals and $34.91 \%$ for teachers. Table 2 details the response rate for principals by region.

Table 2

Principals’ Response Rate by Region $(N=57)$

\begin{tabular}{lccc} 
Region & $\begin{array}{c}\text { Agreed to } \\
\text { Participate } \\
(N)\end{array}$ & $\begin{array}{c}\text { Responded } \\
(N)\end{array}$ & $\begin{array}{c}\text { Response } \\
\text { Rate } \\
\text { (Percent) }\end{array}$ \\
\hline North & 25 & 9 & 36.00 \\
Central & 26 & 17 & 65.38 \\
South & 30 & 31 & 96.77 \\
Total & 81 & 57 & 70.37 \\
\hline
\end{tabular}

Response rates from faculty of individual schools ranged from $4 \%$ to $76.09 \%$. Table 3 details the percentage of response rates per school.

Table 3

Faculty Percentage of Response Rates per School $(N=57)$

\begin{tabular}{ccc}
\hline $\begin{array}{c}\text { Response } \\
\text { Rate }\end{array}$ & $N$ & Percent \\
\hline $4-15 \%$ & 8 & 14.03 \\
$15-30 \%$ & 15 & 26.32 \\
$31-50 \%$ & 24 & 42.12 \\
$51-76 \%$ & 10 & 17.54 \\
Total & 57 & 100.01 \\
\hline
\end{tabular}

School Climate Survey results consist of public information readily available on the school district's web site. The researcher compiled the School Climate Survey results for the 57 schools included in the study. These data were also imported into an SPSS file for analysis. 


\section{Statistical Treatment}

The general linear model was used to test each specific research hypothesis. Full and restricted models written to reflect each specific research hypothesis were tested to determine whether the specific research hypotheses should be accepted or rejected. An F test was used to determine whether the $R^{2}$ of the full and restricted models were significantly different at an alpha level of .05. The researcher set the alpha level at .05 in accordance with the generally accepted level for use in the social sciences. Additionally, the researcher selected a medium effect size of $f^{2}=.15$ as defined by Cohen (1977). Following are the full and restricted models written to test each Specific Research Hypothesis. In these models, LS refers to the elementary school principals' leadership style and was operationally defined as their scores on each of the leadership dimensions measured by the MLQ Form 5X. Statistical analyses were conducted for each of these dimensions of leadership style. EI refers to the elementary school principals' level of emotional intelligence, and was operationally defined as their total standard score on the EQ-i. School culture is referred is as SC and was operationally defined as the results on the School Climate Surveys as completed by the teachers at each school. Statistical analyses for school culture were conducted for each of the categories identified by the researcher as either relating to teacher professionalism and goal setting or professional treatment by administration aligned with two subscales of the School Culture Survey developed by Saphier and King (1985).

Specific Research Hypothesis 1. The EQ-i scores of elementary school principals account for a significant amount of unique variance in predicting their scores on the MLQ Form 5X. 
Full Model 1: $\mathrm{LS}=\mathrm{a}_{0} \mathrm{U}+\mathrm{a}_{1} \mathrm{EI}+\mathrm{E}_{1}$

Restricted Model 1: $\mathrm{LS}=\mathrm{a}_{0} \mathrm{U}+\mathrm{E}_{2}$

Specific Research Hypothesis 2. The interaction between the EQ-i scores of public elementary school principals and their scores on the MLQ Form $5 \mathrm{X}$ accounts for a significant amount of unique variance in predicting school culture over and above the additives.

Full Model 2: $\mathrm{SC}=\mathrm{a}_{0} \mathrm{U}+\mathrm{a}_{2} \mathrm{EI}+\mathrm{a}_{3} \mathrm{LS}+\mathrm{a}_{4}(\mathrm{EI} * \mathrm{LS})+\mathrm{E}_{3}$

Restricted Model 2: $\mathrm{SC}=\mathrm{a}_{0} \mathrm{U}+\mathrm{a}_{5} \mathrm{EI}+\mathrm{a}_{6} \mathrm{LS}+\mathrm{E}_{4}$

Specific Research Hypothesis 3. The public elementary school principals' scores on the MLQ Form 5X account for a significant amount of unique variance in predicting school culture over and above their EQ-i scores.

Full Model 3: $\quad \mathrm{SC}=\mathrm{a}_{0} \mathrm{U}+\mathrm{a}_{7} \mathrm{LS}+\mathrm{a}_{8} \mathrm{EI}+\mathrm{E}_{5}$

Restricted Model 3: $\mathrm{SC}=\mathrm{a}_{0} \mathrm{U}+\mathrm{a}_{9} \mathrm{EI}+\mathrm{E}_{6}$

Specific Research Hypothesis 4. The public elementary school principals' EQ-i scores account for a significant amount of unique variance in predicting school culture over and above their scores on the MLQ Form $5 \mathrm{X}$.

Full Model 4: $\quad \mathrm{SC}=\mathrm{a}_{0} \mathrm{U}+\mathrm{a}_{10} \mathrm{LS}+\mathrm{a}_{11} \mathrm{EI}+\mathrm{E}_{7}$

Restricted Model 4: $\mathrm{SC}=\mathrm{a}_{0} \mathrm{U}+\mathrm{a}_{12} \mathrm{LS}+\mathrm{E} 8$

Statistical Hypothesis. Over and above the influence of school grade (SG), scores on the MLQ Form 5X account for a significant amount of unique variance in predicting school culture.

Full Model 4: $\quad \mathrm{SC}=\mathrm{a}_{0} \mathrm{U}+\mathrm{a}_{13} \mathrm{SG}+\mathrm{a}_{14} \mathrm{LS}+\mathrm{E} 9$

Restricted Model 4: $\mathrm{SC}=\mathrm{a}_{0} \mathrm{U}+\mathrm{a}_{15} \mathrm{LS}+\mathrm{E}_{10}$ 
Power analyses were conducted to determine the power level achieved with an $N$ size of 57. Utilizing the specific research hypothesis containing the largest number of variables in the full regression model (Specific Research Hypotheses 2 containing four variables or $\mathrm{m} 1=4)$, with $\alpha=.05, f^{2}=.15, \mathrm{U}=1, \mathrm{~V}=53$, and $\mathrm{L}=7.95$, Cohen's (1977) power tables reflect that power is approximately .80 with an $N$ of 57 .

\section{Limitations}

Although the data from the School Climate Survey to be used in the study are readily accessible on the district's web site; and, although the researcher's role as a principal within the school district facilitated gathering survey responses from principals, some data gathering limitations were identified. Data gathered are obviously dependent on participant response. Several issues could have affected participants' willingness to complete the surveys, including lack of time or lack of interest in the subject (Rogelberg \& Luong, 1998). Accordingly, although a response rate of $70.37 \%$ was obtained for principals, the overall response rate for teachers was only $34.91 \%$. Additionally, the response rate for principals by region ranged from $36.00 \%$ to $96.77 \%$, and the response rates for teachers by school ranged from $4 \%$ to $76 \%$, thereby yielding a disparate number of responses from faculty members among schools. Data from the School Climate Survey was also limited to 56 of the 57 schools because the results of the faculty responses to the survey were not available for one of the schools included in the study. 


\section{CHAPTER IV}

\section{RESULTS}

The variables included in this study were emotional intelligence, transformational leadership and school culture. Statistical analyses were utilized to determine whether or not a relationship among these variables could be supported, and more specifically, whether or not emotional intelligence and transformational leadership would be found to contribute unique variance in predicting school culture as was hypothesized. This chapter addresses the results of the statistical tests of the stated hypotheses, and provides descriptive statistics regarding the study participants and their schools.

\section{Descriptive Statistics}

\section{Emotional Intelligence}

Results of the EQ-i are reported in standard scores as a total score, and as individual scores for 15 factors or sub-categories within each of the five categories measured. Standard scores are calculated from raw scores and normed by age such that each scale has a mean of 100 and a standard deviation of 15 (Bar-On, 2011). Table 4 depicts a summary of the mean EQ-i standard scores, and the standard deviations for the 57 principals in the study. The mean total standard score for the study participants was 107.56 $(S D=12.27)$. Mean scores for the 15 sub-categories of emotional intelligence ranged from $96.30(S D=13.07)$ in flexibility to $111.44(S D=16.52)$ in self-regard. The five main categories of emotional intelligence measured yielded mean standard scores as follows: self-perception, $107.93(S D=12.02)$; self-expression, $105.4(S D=14.83)$; interpersonal, $109.65(S D=10.56)$; decision making, $107.84(S D=12.12)$; and stress management, $102.02(S D=13.35)$. Results suggest that the emotional intelligence of the 
principals in the study as measured in the self-report method utilized falls within the average range when compared to the norm population.

Table 4

Summary of the EQ-i Standard Scores for Principals for the 5 Categories and 15 SubCategories Measured $(N=57)$

\begin{tabular}{lcc}
\hline Measure & $M$ & $S D$ \\
\hline Self-Perception & 107.93 & 12.02 \\
Self-Regard & 111.44 & 16.52 \\
Self-Actualization & 108.00 & 12.36 \\
Emotional Self-Awareness & 103.32 & 12.00 \\
Self-Expression & 105.40 & 14.83 \\
Emotional Expression & 99.68 & 14.89 \\
Assertiveness & 107.53 & 12.60 \\
Independence & 107.37 & 15.62 \\
Interpersonal & 109.65 & 10.56 \\
Interpersonal Relationships & 108.44 & 11.65 \\
Empathy & 108.14 & 11.17 \\
Social Responsibility & 109.46 & 11.64 \\
Decision Making & 107.84 & 12.12 \\
Problem Solving & 106.05 & 13.79 \\
Reality Testing & 106.67 & 13.13 \\
Impulse Control & 105.93 & 11.76 \\
Stress Management & 102.02 & 13.35 \\
Flexibility & 96.30 & 13.07 \\
Stress Tolerance & 104.21 & 14.51 \\
Optimism & 105.72 & 13.34 \\
Total Standard Score & 107.56 & 12.27 \\
\hline & & \\
\hline
\end{tabular}




\section{Multifactor Leadership Questionnaire}

The mean scores and standard deviations of the faculty perceptions of leadership behaviors as measured on the MLQ Form 5X (Bass \& Avolio, 2004) for the 57 principals in the study are depicted in Table 5. Mean scores were derived from the mean scores per principal from faculty responses with response rates per school ranging from $4 \%$ to $76 \%$. Mean scores are based on responses for items measuring each leadership behavior utilizing a 5-point Likert scale ranging from 0 for "not at all", to 4 for "frequently, if not always”. Mean scores ranged from $0.50(S D=0.80)$ for Laissez-faire leadership characterized as Passive-Avoidant, to $3.33(S D=0.87)$ for the Inspirational Motivation dimension of transformational leadership. Overall, the highest scores, ranging from 2.53 $(S D=1.00)$ for Individualized Consideration to $3.33(S D=0.87)$ for Inspirational Motivation were within the leadership measures characterized as transformational and for Contingent Reward $(3.11, S D=0.91)$ characterized as transactional.

Bass and Avolio’s (2004) MLQ Manual provides corresponding percentiles for the mean scores on each of the leadership behaviors measured when compared to the norm population. These percentile rankings for the mean scores of the principals in the study are detailed in Table 5, and reveal that the principals' mean scores for 4 of the 5 leadership behaviors identified as transformational by Bass and Avolio (2004) place them at or above the $50^{\text {th }}$ percentile when compared to the norm population. The percentile ranking for Individualized Consideration was 30. The principals' ranking for the leadership behaviors identified as transactional were at the $60^{\text {th }}$ percentile for Contingent Reward and the $65^{\text {th }}$ percentile for Management-by-Exception-Active. Principals were 
placed at the $50^{\text {th }}$ percentile for both leadership behaviors categorized as PassiveAvoidant.

Table 5

Summary of Scores on the MLQ Form $5 X(N=850)$

\begin{tabular}{lccc}
\hline Leadership Measure & $M$ & $S D$ & Percentile \\
\hline Transformational & & & \\
$\quad$ Idealized Influence-Attributes & 3.10 & 0.93 & 50 \\
$\quad$ Idealized Influence-Behaviors & 3.08 & 0.85 & 50 \\
$\quad$ Inspirational Motivation & 3.33 & 0.87 & 65 \\
$\quad$ Intellectual Stimulation & 2.74 & 1.01 & 50 \\
$\quad$ Individualized Consideration & 2.53 & 1.00 & 30 \\
Transactional & & & \\
$\quad$ Contingent Reward & 3.11 & 0.91 & 60 \\
$\quad$ Management-by-Exception-Active & 1.97 & 1.10 & 65 \\
Passive-Avoidant & & & \\
$\quad$ Management-by-Exception-Passive & 0.96 & 0.86 & 50 \\
$\quad$ Laissez-faire & 0.50 & 0.80 & 50 \\
\hline
\end{tabular}

\section{School Climate Survey}

Miami-Dade County Public Schools' School Climate Survey was used as the measure for school culture. The researcher categorized 11 of the 34 items on the staff survey as addressing Teacher Professionalism and Goal Setting, and 11 of the items as addressing Professional Treatment by Administrators, to align with two of the subscales of the School Culture Survey developed by Saphier and King (1985). Table 6 reflects a summary of the mean percent of "strongly agree" or "agree" responses to items in each of the two categories for 56 of the 57 schools involved in the study. No information 
regarding the staff responses to the School Climate Survey was available on the district's web site for one of the participating schools.

Recognizing that changes in organizational culture evolve over time (Peterson \& Deal, 1998), each principal's length of time at their respective schools was of concern to the researcher in measuring school culture and in testing the relationships between the variables. As such, demographic information collected included the number of years as principal of their current school. One way ANOVA analysis revealed no statistically significant differences in the culture variables by the number of years the principal was at the school for each measure of school culture (Teacher Professionalism and Goal Setting $=F(3,52)=1.45, p=.24$; Professional Treatment by Administrators $=F(3,52)=2.13, p$ $=.11)$.

Table 6

Summary of the School Climate Survey Results $\left(N=56^{*}\right)$

\begin{tabular}{|c|c|c|}
\hline Element of School Culture & $\begin{array}{l}M \text { Percentage of } \\
\text { Strongly Agree or } \\
\text { Agree Responses }\end{array}$ & $S D$ \\
\hline Teacher Professionalism \& Goal Setting & 75.77 & 8.39 \\
\hline Professional Treatment by Administrators & 84.09 & 11.39 \\
\hline
\end{tabular}

\section{School Grades}

Additional descriptive information regarding the participating schools can be gleaned through a review of their school grades based on Florida's School Accountability Reports. The State of Florida Department of Education assigns grades of A, B, C, D, or F to all schools. Calculation of school grades for elementary schools is based on 8 data 
points: the percentage of students demonstrating mastery on the Florida Comprehensive Assessment Test in reading, writing, mathematics and science; the percent of students demonstrating learning gains in reading and mathematics; and the percent of students performing at the lowest $25^{\text {th }}$ percentile in each school who demonstrate learning gains in reading and mathematics (Florida Department of Education, 2013). Table 7 provides a summary of the school grades assigned to the 57 schools involved in the study within Florida's school accountability system.

Table 7

Summary of School Grades Assigned in Florida's Accountability Reports $(N=57)$

\begin{tabular}{lcc}
\hline School Grade & $N$ & Percent \\
\hline A & 28 & 49.12 \\
B & 17 & 29.82 \\
C & 11 & 19.30 \\
D & 1 & 1.75 \\
F & 0 & 0.00 \\
Total & 57 & 99.99 \\
\hline
\end{tabular}

\section{Results of Testing the Research Hypotheses}

\section{Specific Research Hypothesis 1}

The results of the statistical analysis utilizing the full and restricted models developed for Specific Research Hypothesis 1, the EQ-i scores of elementary school principals account for a significant amount of variance in predicting their scores on the 
MLQ Form 5X, are depicted in Table 8. Significant positive associations were found between emotional intelligence and Idealized Influence-Attributes $(\beta=.23, p=<.05)$, and between emotional intelligence and Idealized Influence-Behaviors $(\beta=.34, p=<$ $.01)$, Inspirational Motivation $(\beta=.39, p=<.01)$ and Contingent Reward $(\beta=.33, p=<$ $.01)$. Emotional intelligence revealed the most powerful relationship with Inspirational Motivation. No significant associations were found between emotional intelligence and any of the other leadership measures tested $(p s>.05)$. Consequently, Specific Research Hypothesis 1 was partially supported.

Table 8

Summary of Linear Regressions with Emotional Intelligence Predicting Leadership ( $N=$ 57)

\begin{tabular}{lcccc}
\hline \multicolumn{1}{c}{ Variables } & $r^{2}$ & $B$ & $S E B$ & $\beta$ \\
\hline $\begin{array}{l}\text { Emotional Intelligence predicting: } \\
\text { Transformational }\end{array}$ & & & & \\
$\quad$ Idealized Influence-Attributes & .053 & .012 & .007 & $.230^{*}$ \\
Idealized Influence-Behaviors & .112 & .014 & .005 & $.335^{* *}$ \\
Inspirational Motivation & .153 & .018 & .006 & $.391^{* *}$ \\
Intellectual Stimulation & .028 & .008 & .006 & .168 \\
Individualized Consideration & .029 & .007 & .006 & .169 \\
Transactional & & & & .006 \\
Contingent Reward & .111 & .014 & .005 & $.333^{* *}$ \\
Management-by-Exception-Active & .000 & .000 & .004 & -.009 \\
Passive-Avoidant & & & & \\
Management-by-Exception-Passive & .010 & -.004 & .005 & -.099 \\
Laissez-faire & .007 & -.003 & .005 & -.081 \\
\hline
\end{tabular}

Note: $* p=<.05, * * p=<.01$ 


\section{Specific Research Hypothesis 2}

In testing for Specific Research Hypothesis 2, where the interaction between the EQ-i scores of public elementary school principals and their scores on the MLQ Form 5X would account for a significant amount of unique variance in predicting school culture over and above the additives, statistical analysis of the cross product of emotional intelligence with each measure of leadership revealed no significant associations. The $R^{2}$, unstandardized coefficients, standard errors and standardized coefficients resulting from a linear regression analysis of the full and restricted models utilized to test this hypothesis are included in Table 9. 
Table 9

Linear Regression of the Interaction of Leadership and Emotional Intelligence Predicting School Culture $(N=57)$

\begin{tabular}{|c|c|c|c|c|c|c|c|c|}
\hline \multirow{2}{*}{$\begin{array}{c}\text { Interaction between } \\
\text { Leadership Measure and } \\
\text { Emotional Intelligence }\end{array}$} & \multicolumn{8}{|c|}{ School Culture } \\
\hline & \multicolumn{4}{|c|}{$\begin{array}{c}\text { Teacher Professionalism and } \\
\text { Goal Setting }\end{array}$} & \multicolumn{4}{|c|}{$\begin{array}{c}\text { Professional Treatment } \\
\text { by Administrators }\end{array}$} \\
\hline Transformational & $r^{2}$ & $B$ & SE B & $\beta$ & $r^{2}$ & $B$ & $S E B$ & $\beta$ \\
\hline $\begin{array}{l}\text { Idealized Influence- } \\
\text { Attributes }\end{array}$ & .251 & .133 & .135 & 1.423 & .450 & .018 & .157 & .145 \\
\hline $\begin{array}{l}\text { Idealized Influence- } \\
\text { Behaviors }\end{array}$ & .206 & .199 & .169 & 2.004 & .375 & -.089 & .204 & -.662 \\
\hline $\begin{array}{l}\text { Inspirational } \\
\text { Motivation }\end{array}$ & .228 & .203 & .147 & 2.212 & .428 & .110 & .172 & .883 \\
\hline Intellectual Stimulation & .197 & .205 & .158 & 1.987 & .305 & -.073 & .199 & -.521 \\
\hline $\begin{array}{l}\text { Individualized } \\
\text { Consideration }\end{array}$ & .219 & .143 & .170 & 1.320 & .412 & -.071 & .200 & -.480 \\
\hline \multicolumn{9}{|l|}{ Transactional } \\
\hline Contingent Reward & .247 & .283 & .149 & 2.803 & .392 & .100 & .182 & .732 \\
\hline $\begin{array}{l}\text { Management-by- } \\
\text { Exception-Active }\end{array}$ & .039 & .086 & .259 & .570 & .013 & -.071 & .357 & -.345 \\
\hline \multicolumn{9}{|l|}{ Passive-Avoidant } \\
\hline $\begin{array}{l}\text { Management-by- } \\
\text { Exception-Passive }\end{array}$ & .243 & -.105 & .164 & -.706 & .355 & -.209 & .205 & -1.034 \\
\hline Laissez-faire & .278 & -.119 & .177 & -.756 & .473 & .013 & .205 & .059 \\
\hline
\end{tabular}

Note: ${ }^{*} p=<.05, * * p=<.01$

\section{Specific Research Hypothesis 3}

Because no significant difference between the $R^{2}$ of the full model and $R^{2}$ of the restricted model at the alpha level of .05 was found, Specific Research Hypothesis 2 was rejected; the researcher proceeded to test for the main effects of transformational leadership and emotional intelligence (McNeil et al., 2012). Specific Research 
Hypothesis 3, where the public elementary school principals' scores on the MLQ Form $5 \mathrm{X}$ would account for a significant amount of variance in predicting school culture over and above their EQ-i scores, was developed based on the third research question. The full and restricted models utilized to test this hypothesis were as follows:

Full Model 3: $\quad \mathrm{SC}=\mathrm{a}_{0} \mathrm{U}+\mathrm{a}_{7} \mathrm{LS}+\mathrm{a}_{8} \mathrm{EI}+\mathrm{E}_{5}$

Restricted Model 3: $\mathrm{SC}=\mathrm{a}_{0} \mathrm{U}+\mathrm{a}_{9} \mathrm{EI}+\mathrm{E}_{6}$

The transformational, transactional and passive-avoidant leadership measures as categorized by the MLQ Form 5X were grouped together for this analysis (Bass \& Avolio, 2004). Table 10 details the results of the hierarchical regression utilized to test the main effects of transformational leadership measures in predicting school culture. The Teacher Professionalism and Goal Setting dimension of school culture was tested first. For step 1, EQ-i was entered into the regression equation where $F(1,54)=2.00, p=$ $.08, R^{2}=.04$. In the second step, the five transformational leadership measures were entered, $F(6,49)=2.79, p=.01, R^{2}=.25$. The hypothesis was supported, although none of the separate items were significant predictors. Thus, $25.4 \%$ of the variance in the dependent variable was explained.

Secondly, the dimension of school culture categorized as Professional Treatment by Administrators was tested. For step 1, EQ-i was entered into the regression equation where $F(1,54)=.68, p=.21, R^{2}=.01$. In the second step, the five transformational leadership measures were entered, where $F(6,49)=7.90, p=.00, R^{2}=.49$. The hypothesis was supported, and two of the separate items were significant predictors. A positive association was supported for Idealized Influence-Attributes $(\beta=.81, p=.03)$, 
and a significant negative association was supported for Intellectual Stimulation $(\beta=$ -

$.58, p=.03)$. Thus, $49.1 \%$ of the variance in the dependent variable was explained.

Table 10

Summary of Hierarchical Regression Analysis for Transformational Leadership Variables Predicting School Culture $(N=57)$

\begin{tabular}{|c|c|c|c|c|c|c|}
\hline \multirow{3}{*}{ Variable } & \multicolumn{6}{|c|}{ School Culture } \\
\hline & \multicolumn{3}{|c|}{$\begin{array}{c}\text { Teacher Professionalism } \\
\text { and Goal Setting }\end{array}$} & \multicolumn{3}{|c|}{$\begin{array}{c}\text { Professional Treatment } \\
\text { by Administrators }\end{array}$} \\
\hline & $B$ & $S E B$ & $\beta$ & $B$ & $S E B$ & $\beta$ \\
\hline \multicolumn{7}{|l|}{ Step 1} \\
\hline Emotional Intelligence & .129 & .091 & .189 & .103 & .125 & .111 \\
\hline \multicolumn{7}{|l|}{ Step 2} \\
\hline Idealized Influence-Attributes & 10.734 & 6.657 & .804 & 14.667 & 7.460 & $.810^{*}$ \\
\hline Idealized Influence-Behaviors & 2.540 & 5.712 & .160 & 4.076 & 6.402 & .190 \\
\hline Inspirational Motivation & -4.251 & 7.196 & -.291 & -.436 & 8.065 & -.022 \\
\hline Intellectual Stimulation & -5.215 & 5.270 & -.359 & -11.402 & 5.906 & $-.579 *$ \\
\hline Individualized Consideration & 1.753 & 6.850 & .116 & 5.670 & 7.677 & .276 \\
\hline
\end{tabular}

Note. $R^{2}=.04$ for Step $1 ; \Delta R^{2}=.22$ for Step 2 for Teacher Professionalism and Goal Setting. $R^{2}=.01$ for Step $1 ; \Delta R^{2}=.48$ for Step 2 for Professional Treatment by Administrators.

$* p=<.05$.

The main effects of transactional leadership measures in predicting school culture were analyzed in the same manner. The results of the hierarchical regression analysis are provided in Table 11. Again, each of the dimensions of school culture was tested separately. For Teacher Professionalism and Goal Setting, in step 1, EQ-i was entered into the regression equation where $F(1,54)=2.00, p=.08, R^{2}=.04$. In the second step, the two transactional leadership measures were entered, where $F(3,52)=4.49, p=.003$, $R^{2}=.21$. The hypothesis was supported, and the separate item of Contingent Reward 
was a significant predictor $(\beta=.44, p=.001)$. Thus, $20.6 \%$ of the variance in the dependent variable was explained.

For the dimension of school culture categorized as Professional Treatment by Administrators, in step 1, EQ-i was entered into the regression equation where $F(1,54)=$ $.68, p=.21, R^{2}=.01$. In the second step, the two transactional leadership measures were entered, where $F(3,52)=11.56, p=.00, R^{2}=.40$. The hypothesis was supported, and a significant positive association was supported for Contingent Reward $(\beta=.67, p=<$ $.01)$. Thus, $40.0 \%$ of the variance in the dependent variable was explained.

\section{Table 11}

Summary of Hierarchical Regression Analysis for Transactional Leadership Variables Predicting School Culture $(N=57)$

\begin{tabular}{cccccc} 
Variable & \multicolumn{4}{c}{$\begin{array}{c}\text { School Culture } \\
\text { Teacher Professionalism } \\
\text { and Goal Setting }\end{array}$} & $\begin{array}{c}\text { Professional Treatment } \\
\text { by Administrators }\end{array}$ \\
\hline B & $S E B$ & $\beta$ & $B$ & $S E B$ & $\beta$
\end{tabular}

Step 1

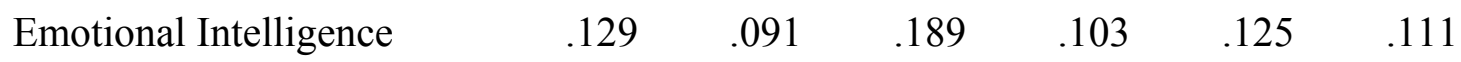

Step 2

\begin{tabular}{lllllll} 
Contingent Reward & 7.172 & 2.161 & $.442 * *$ & 14.778 & 2.549 & $.671 * *$ \\
$\begin{array}{l}\text { Management-by-Exception }- \\
\text { Active }\end{array}$ & -2.451 & 2.814 & -.109 & -3.417 & 3.319 & -.112 \\
\hline
\end{tabular}

Note. $R^{2}=.04$ for Step $1 ; \Delta R^{2}=.17$ for Step 2 for Teacher Professionalism and Goal Setting. $R^{2}=.01$ for Step $1 ; \Delta R^{2}=.39$ for Step 2 for Professional Treatment by Administrators.

$* p=<.05, * * p=<.01$.

Finally, the results of the third hierarchical regression analysis conducted to test for the main effects of the Passive-Avoidant leadership variables in predicting school culture are detailed in Table 12. For Teacher Professionalism and Goal Setting, step 1, 
EQ-i was entered into the regression equation where $F(1,54)=2.00, p=.08, R^{2}=.04$. In the second step, the two passive-avoidant leadership measures were entered, where $F(3$, $52)=6.63, p=.00, R^{2}=.28$. The hypothesis was supported, and a significant negative relationship was supported for the separate item of Laissez-faire $(\beta=-.38, p=.05)$. Thus, $27.7 \%$ of the variance in the dependent variable was explained.

For Professional Treatment by Administrators, in step 1, EQ-i was entered into the regression equation where $F(1,54)=.68, p=.21, R^{2}=.01$. In the second step, the two passive-avoidant leadership measures were entered, where $F(3,52)=15.57, p=.00$, $R^{2}=.48$. The hypothesis was supported, and a significant negative association was supported for Laissez-faire $(\beta=-.68, p=.00)$. Thus, $47.3 \%$ of the variance in the dependent variable was explained.

Table 12

Summary of Hierarchical Regression Analysis for Passive-Avoidant Leadership Variables Predicting School Culture $(N=57)$

\begin{tabular}{|c|c|c|c|c|c|c|}
\hline \multirow{3}{*}{ Variable } & \multicolumn{6}{|c|}{ School Culture } \\
\hline & \multicolumn{3}{|c|}{$\begin{array}{l}\text { Teacher Professionalism } \\
\text { and Goal Setting }\end{array}$} & \multicolumn{3}{|c|}{$\begin{array}{c}\text { Professional Treatment } \\
\text { by Administrators }\end{array}$} \\
\hline & $B$ & SE B & $\beta$ & $B$ & $S E B$ & $\beta$ \\
\hline \multicolumn{7}{|l|}{ Step 1} \\
\hline Emotional Intelligence & .129 & .091 & .189 & .103 & .125 & .111 \\
\hline \multicolumn{7}{|l|}{ Step 2} \\
\hline $\begin{array}{l}\text { Management-by-Exception- } \\
\text { Passive }\end{array}$ & -2.139 & 3.704 & -.129 & .074 & 4.290 & .003 \\
\hline Laissez-faire & -6.539 & 3.851 & $-.379 *$ & -16.034 & 4.462 & $-.684 * *$ \\
\hline
\end{tabular}

Note. $R^{2}=.04$ for Step $1 ; \Delta R^{2}=.24$ for Step 2 for Teacher Professionalism and Goal Setting. $R^{2}=.01$ for Step $1 ; \Delta R^{2}=.46$ for Step 2 for Professional Treatment by Administrators.

${ }^{*} p=<.05,{ }^{* *} p=<.01$. 


\section{Specific Research Hypothesis 4}

The research hypotheses and full and restricted models utilized to test for main effects of emotional intelligence based on the fourth research question were as follows.

Specific Research Hypothesis 4. The public elementary school principals' EQ-i scores account for a significant amount of variance in predicting school culture over and above their scores on the MLQ Form 5X.

Full Model 4: $\quad \mathrm{SC}=\mathrm{a}_{0} \mathrm{U}+\mathrm{a}_{10} \mathrm{LS}+\mathrm{a}_{11} \mathrm{EI}+\mathrm{E}_{7}$

Restricted Model 4: $\mathrm{SC}=\mathrm{a}_{0} \mathrm{U}+\mathrm{a}_{12} \mathrm{LS}+\mathrm{E}_{8}$

This analysis was also conducted in three phases by grouping the transformational, transactional and passive-avoidant leadership measures as categorized by the MLQ Form 5X together for each hierarchical regression (Bass \& Avolio, 2004). Table 13 details the results of the hierarchical regression utilized to test the main effects of emotional intelligence over and above the transformational leadership measures in predicting school culture. First, the dimension of school culture categorized as Teacher Professionalism and Goal Setting was tested. For step 1, the five transformational leadership measures were entered into the regression equation where $F(5,50)=3.28, p=$ $.006, R^{2}=.25$. In the second step, EQ-i was entered, where $F(6,49)=2.79, p=.01, R^{2}=$ .25. The hypothesis was supported, and none of the separate items were significant predictors. Thus, $25.5 \%$ of the variance in the dependent variable was explained.

Secondly, the dimension of school culture categorized as Professional Treatment by Administrators was tested. For step 1, the five transformational leadership measures were entered, where $F(5,50)=9.54, p=.00, R^{2}=.49$. In the second step, EQ-i was entered into the regression equation where $F(6,49)=7.90, p=.00, R^{2}=.49$. The 
hypothesis was supported, and two of the separate items were significant predictors. A significant positive association was supported for Idealized Influence-Attributes $(\beta=.84$, $p=.02$ ), and a significant negative association was supported for Intellectual Stimulation ( $\beta=-.58, p=.03$ ). Thus, $49.2 \%$ of the variance in the dependent variable was explained.

Table 13

Summary of Hierarchical Regression Analysis for Emotional Intelligence Predicting School Culture Over and Above Transformational Leadership Variables $(N=57)$

\begin{tabular}{lccccccc}
\hline \multirow{2}{*}{ Variable } & \multicolumn{6}{c}{$\begin{array}{c}\text { School Culture } \\
\text { and Goal Setting }\end{array}$} & \multicolumn{4}{c}{$\begin{array}{c}\text { Professional Treatment } \\
\text { by Administrators }\end{array}$} \\
\hline & $B$ & $S E B$ & $\beta$ & $B$ & $S E B$ & $\beta$ \\
Step 1 & & & & & & \\
$\quad$ Idealized Influence-Attributes & 10.094 & 6.564 & .757 & 15.260 & 7.344 & $.843^{*}$ \\
Idealized Influence-Behaviors & 2.639 & 5.682 & .167 & 3.984 & 6.358 & .185 \\
Inspirational Motivation & -2.052 & 6.468 & -.140 & -2.473 & 7.237 & -.124 \\
Intellectual Stimulation & -5.089 & 5.241 & -.351 & -11.518 & 5.864 & $-.584^{*}$ \\
Individualized Consideration & .469 & 6.576 & .031 & 6.859 & 7.357 & .334
\end{tabular}

Step 2

$\begin{array}{llllllll}\text { Emotional Intelligence } & .074 & .104 & .108 & -.068 & .116 & -.074\end{array}$

Note. $R^{2}=.25$ for Step $1 ; \Delta R^{2}=.008$ for Step 2 for Teacher Professionalism and Goal Setting. $R^{2}=.49$ for Step $1 ; \Delta R^{2}=.004$ for Step 2 for Professional Treatment by Administrators.

${ }^{*} p=<.05,{ }^{* *} p=<.01$.

The same procedures were used to analyze the main effects of emotional intelligence in predicting school culture over and above the transactional leadership measures. The results of the hierarchical regression are provided in Table 14. For Teacher Professionalism and Goal Setting, in step 1, the two transactional leadership measures entered into the regression equation where $F(2,53)=6.801, p=.001, R^{2}=.20$. 
In the second step, EQ-i was entered, where $F(3,52)=4.49, p=.003, R^{2}=.21$. The hypothesis was supported, and the separate item of Contingent Reward was a significant predictor $(\beta=.46, p=.00)$. Thus, $20.5 \%$ of the variance in the dependent variable was explained.

For the dimension of school culture categorized as Professional Treatment by Administrators, in step 1, the two transactional leadership measures were entered, where $F(2,53)=16.84, p=.00, R^{2}=.39$. In the second step, EQ-i was entered into the regression equation where $F(3,52)=11.56, p=.00, R^{2}=.40$. The hypothesis was supported, and a significant positive association was supported for Contingent Reward ( $\beta$ $=.63, p=.00)$. Thus, $40.1 \%$ of the variance in the dependent variable was explained.

\section{Table 14}

Summary of Hierarchical Regression Analysis for Emotional Intelligence Predicting School Culture Over and Above Transactional Leadership Variables $(N=57)$

\begin{tabular}{|c|c|c|}
\hline \multirow{3}{*}{ Variable } & \multicolumn{2}{|c|}{ School Culture } \\
\hline & $\begin{array}{c}\text { Teacher Professionalism } \\
\text { and Goal Setting }\end{array}$ & $\begin{array}{c}\text { Professional Treatment } \\
\text { by Administrators }\end{array}$ \\
\hline & $B \quad S E B \quad \beta$ & $\begin{array}{lll}B & S E B & \beta\end{array}$ \\
\hline
\end{tabular}

Step 1

$\begin{array}{lllllll}\text { Contingent Reward } & 7.403 & 2.014 & .457 * * & 13.904 & 2.396 & .632 * * \\ \begin{array}{l}\text { Management-by-Exception }- \\ \text { Active }\end{array} & -2.479 & 2.788 & -.110 & -3.310 & 3.318 & -.109\end{array}$

Step 2

\begin{tabular}{lllllll} 
Emotional Intelligence & .028 & .090 & .041 & -.106 & .106 & -.115 \\
\hline
\end{tabular}

Note. $R^{2}=.20$ for Step $1 ; \Delta R^{2}=.00$ for Step 2 for Teacher Professionalism and Goal Setting. $\quad R^{2}=.39$ for Step $1 ; \Delta R^{2}=.01$ for Step 2 for Professional Treatment by Administrators.

$* p=<.05, * * p=<.01$. 
Lastly, Table 15 depicts the results of the third hierarchical regression analysis conducted to test for the main effects of emotional intelligence in predicting school culture over and above the Passive-Avoidant leadership variables. In step 1 for Teacher Professionalism and Goal Setting, the two passive-avoidant leadership measures were entered into the regression equation where $F(2,53)=9.104, p=.00, R^{2}=.26$. In the second step, EQ-i was entered, where $F(3,52)=6.63, p=.00, R^{2}=.28$. The hypothesis was supported, and a significant negative relationship was supported for the separate item of Laissez-faire ( $\beta=-.38, p=.04)$. Thus, $27.7 \%$ of the variance in the dependent variable was explained.

For Professional Treatment by Administrators, in step 1, the two passive-avoidant leadership measures were entered into the regression equation where $F(2,53)=23.52, p$ $=.00, R^{2}=.47$. In the second step, EQ-i was entered, where $F(3,52)=15.57, p=.00, R^{2}$ $=.47$. The hypothesis was supported, and a significant negative association was supported for Laissez-faire $(\beta=-.69, p=.00)$. Thus, $47.3 \%$ of the variance in the dependent variable was explained. 
Table 15

Summary of Hierarchical Regression Analysis for Emotional Intelligence Predicting School Culture Over and Above the Passive-Avoidant Leadership Variables $(N=57)$

\section{School Culture}

Variable

Teacher Professionalism

Professional Treatment and Goal Setting

$\begin{array}{llllll}B & S E B & \beta & B & S E B & \beta\end{array}$

Step 1

Management-by-Exception-

Passive

3.718

$-.140$

$-.023$

4.258

Laissez-faire

$-6.580$

3.870

$-.381 * \quad-16.055$

$4.431-.685^{* *}$

Step 2

Emotional Intelligence .099 .081 .146 .050 .094 .054

Note. $R^{2}=.26$ for Step $1 ; \Delta R^{2}=.02$ for Step 2 for Teacher Professionalism and Goal Setting. $R^{2}=.47$ for Step $1 ; \Delta R^{2}=.00$ for Step 2 for Professional Treatment by Administrators.

$* p=<.05, * * p=<.01$.

\section{Statistical Hypothesis}

Finally, to control for alternative explanations, the statistical hypothesis, over and above the influence of school grade, scores on the MLQ Form 5X account for a significant amount of variance in predicting school culture, was tested using the following full and restricted models.

Full Model 4: $\quad \mathrm{SC}=\mathrm{a}_{0} \mathrm{U}+\mathrm{a}_{13} \mathrm{SG}+\mathrm{a}_{14} \mathrm{LS}+\mathrm{E}_{9}$

Restricted Model 4: $\mathrm{SC}=\mathrm{a}_{0} \mathrm{U}+\mathrm{a}_{15} \mathrm{LS}+\mathrm{E}_{10}$

Once again, the leadership measures of transformational, transactional and passiveavoidant categorized by the MLQ Form 5X were grouped together for each hierarchical regression (Bass \& Avolio, 2004). The results of the hierarchical regression utilized to test the effects of transformational leadership over and above school grades in predicting 
school culture are provided in Table 16. First the dimension of school culture categorized as Teacher Professionalism and Goal Setting was tested. For step 1, the school grade variable was entered into the regression equation where $F(1,54)=5.66, p=$ $.01, R^{2}=.095$. In the second step, the five transformational leadership measures were entered, where $F(6,49)=4.28, p=.001, R^{2}=.34$. The hypothesis was supported, but none of the separate variables of transformational leadership were significant predictors. Thus, $34.4 \%$ of the variance in the dependent variable was explained.

Secondly, the dimension of school culture categorized as Professional Treatment by Administrators was tested. For step 1, the school grade was entered, where $F(1,54)=$ $.795, p=.19, R^{2}=.02$. In the second step, the five transformational leadership measures were entered into the regression equation where $F(6,49)=8.32, p=.00, R^{2}=.51$. The hypothesis was supported, and two of the separate items were significant predictors. A significant positive association was supported for Idealized Influence-Attributes $(\beta=.79$, $p=.03$ ), and a significant negative association was supported for Intellectual Stimulation $(\beta=-.56, p=.03)$. Thus, $50.5 \%$ of the variance in the dependent variable was explained. 
Table 16

Summary of Hierarchical Regression Analysis the Transformational Leadership

Variables Predicting School Culture Over and Above School Grade $(N=57)$

School Culture

Variable

Teacher Professionalism Professional Treatment and Goal Setting

$\begin{array}{llllll}B & S E B & \beta & B & S E B & \beta\end{array}$

Step 1

School Grade

$\begin{array}{llllll}3.133 & 1.317 & .308^{* *} & 1.663 & 1.865 & .120\end{array}$

Step 2

$\begin{array}{lcccccc}\text { Idealized Influence-Attributes } & 8.325 & 6.223 & .624 & 14.277 & 7.340 & .788^{*} \\ \text { Idealized Influence-Behaviors } & 1.123 & 5.386 & .071 & 3.141 & 6.354 & .146 \\ \text { Inspirational Motivation } & -2.587 & 6.101 & -.177 & -2.770 & 7.197 & -.139 \\ \text { Intellectual Stimulation } & -4.143 & 4.954 & -.285 & -10.992 & 5.843 & -.558^{*} \\ \text { Individualized Consideration } & 3.647 & 6.311 & .241 & 8.625 & 7.444 & .420\end{array}$

Note. $R^{2}=.10$ for Step $1 ; \Delta R^{2}=.25$ for Step 2 for Teacher Professionalism and Goal

Setting. $R^{2}=.02$ for Step $1 ; \Delta R^{2}=.49$ for Step 2 for Professional Treatment by Administrators.

$* p=<.05$.

The effects of transactional leadership over and above school grade were tested next utilizing a hierarchical regression, and the results are depicted in Table 17. For step 1 in testing the dimension of school culture categorized as Teacher Professionalism and Goal Setting, the school grade variable was entered into the regression equation where $F(1,54)=5.66, p=.01, R^{2}=.095$. In the second step, the two transactional leadership measures were entered, where $F(3,52)=7.64, p=.00, R^{2}=.31$. The hypothesis was supported, and Contingent Reward $(\beta=.47, p=.00)$ was found to be a significant predictor. Thus, $30.6 \%$ of the variance in the dependent variable was explained. 
Secondly, the dimension of school culture categorized as Professional Treatment by Administrators was tested. For step 1, the school grade was entered, where $F(1,54)=$ $.795, p=.19, R^{2}=.02$. In the second step, the two transactional leadership measures were entered into the regression equation where $F(3,52)=11.91, p=.00, R^{2}=.41$. The hypothesis was supported, and Contingent Reward $(\beta=.64, p=.00)$ was a significant predictor. Thus, $40.8 \%$ of the variance in the dependent variable was explained.

Table 17

Summary of Hierarchical Regression Analysis for the Transactional Leadership Variables Predicting School Culture Over and Above School Grade $(N=57)$

School Culture

Variable Teacher Professionalism Professional Treatment and Goal Setting

$\begin{array}{llllll}B & S E B & \beta & B & S E B & \beta\end{array}$

Step 1

School Grade

3.133

1.317

$.308^{* *}$

$1.663 \quad 1.865$

.120

Step 2

\begin{tabular}{lcccccc} 
Contingent Reward & 7.542 & 1.899 & $.465^{* *}$ & 13.985 & 2.382 & $.635^{* *}$ \\
$\begin{array}{l}\text { Management-by-Exception }- \\
\text { Active }\end{array}$ & -2.250 & 2.630 & -.100 & -3.177 & 3.299 & -.104 \\
\hline
\end{tabular}

Note. $R^{2}=.10$ for Step $1 ; \Delta R^{2}=.21$ for Step 2 for Teacher Professionalism and Goal Setting. $R^{2}=.02$ for Step $1 ; \Delta R^{2}=.39$ for Step 2 for Professional Treatment by Administrators. ${ }^{*} p=<.05,{ }^{* *} p=<.01$.

Passive-avoidant leadership measures were entered into the hierarchical regression equation next. The results are detailed in Table 18. For Teacher Professionalism and Goal Setting the school grade variable was entered into the regression equation in step 1 , where $F(1,54)=5.66, p=.01, R^{2}=.095$. The two passiveavoidant leadership measures were entered in the second step, where $F(3,52)=9.12, p=$ 
$.00, R^{2}=.35$. The hypothesis was supported, and a significant negative association was found for Laissez-faire ( $\beta=-.40, p=.03)$. Thus, $34.5 \%$ of the variance in the dependent variable was explained.

Secondly, the dimension of school culture categorized as Professional Treatment by Administrators was tested. For step 1, the school grade was entered into the regression equation, where $F(1,54)=.795, p=.19, R^{2}=.02$. In the second step, the two passive-avoidant leadership measures were entered where $F(3,52)=16.19, p=.00, R^{2}=$ .47. The hypothesis was supported, and a significant negative association was found for Laissez-faire $(\beta=-.69, p=.00)$. Thus, $48.3 \%$ of the variance in the dependent variable was explained.

Table 18

Summary of Hierarchical Regression Analysis for the Passive-Avoidant Leadership Variables Predicting School Culture Over and Above School Grade $(N=57)$

\begin{tabular}{cccccc} 
Variable & \multicolumn{4}{c}{$\begin{array}{c}\text { School Culture } \\
\text { Teacher Professionalism } \\
\text { and Goal Setting }\end{array}$} & $\begin{array}{c}\text { Professional Treatment } \\
\text { by Administrators }\end{array}$ \\
\hline$B$ & $S E B$ & $\beta$ & $B$ & $S E B$ & $\beta$
\end{tabular}

Step 1

$\begin{array}{lllllll}\text { School Grade } & 3.133 & 1.317 & .308^{* *} & 1.663 & 1.865 & .120\end{array}$

Step 2

$\begin{array}{lrrrrrc}\text { Management-by-Exception- } & -1.816 & 3.527 & -.109 & .240 & 4.254 & .011 \\ \text { Passive } & -6.972 & 3.668 & -.404^{*} & -16.255 & 4.424 & -.693^{* *} \\ \text { Laissez-faire } & -.972 & \end{array}$

Note. $R^{2}=.10$ for Step $1 ; \Delta R^{2}=.25$ for Step 2 for Teacher Professionalism and Goal Setting. $R^{2}=.02$ for Step $1 ; \Delta R^{2}=.47$ for Step 2 for Professional Treatment by Administrators.

${ }^{*} p=<.05,{ }^{* *} p=<.01$. 


\section{Summary of Results}

Linear regression analyses revealed partial support for the first research hypothesis, the EQ-i scores of elementary school principals account for a significant amount of variance in predicting their scores on the MLQ Form 5X. Significant positive associations were found between emotional intelligence and Idealized InfluenceAttributes, Idealized Influence-Behaviors, Inspirational Motivation, and Contingent Reward. The second research hypothesis was rejected because a linear regression analysis of the cross product of emotional intelligence with each measure of leadership revealed no significant associations.

The third hypothesis testing the main effects of transformational leadership and emotional intelligence in predicting school culture was supported by the results of the hierarchical regressions conducted. Significant positive associations were found between the transformational and transactional leadership measures and both categories of school culture. Significant negative associations were found between the Passive-Avoidant leadership measures and both categories of school culture. Additionally, Contingent Reward was the strongest predictor of both Teacher Professionalism and Goal Setting and Professional Treatment by Administrators, while Intellectual Stimulation was found to be negatively associated with Professional Treatment by Administrators. Negative associations were also revealed for Laissez-faire and both aspects of school culture.

Support was also found for emotional intelligence as a predictor of school culture over and above leadership measures as stipulated in the fourth hypothesis. Significant positive associations were found between emotional intelligence and both aspects of 
school culture in the hierarchical regressions conducted, which included the transformational, transactional and passive-avoidant leadership measures.

Finally, hierarchical linear regressions conducted to test the statistical hypothesis developed to account for alternative explanations revealed significant positive associations between the transformational and transactional leadership measures and school culture, as well as significant negative associations between Passive-Avoidant leadership measures and school culture over and above school grade. Thus, this hypothesis was supported, thereby strengthening the internal validity of the study (Newman \& Newman, 2005). 


\section{CHAPTER V}

\section{SUMMARY, CONCLUSIONS, AND DISCUSSION}

This chapter provides a summary of the study, a discussion of the conclusions drawn from the findings, theoretical and practical implications suggested by the results, as well as implications for policy and research. Recommendations for further research that could enhance and expand these findings will also be included.

\section{Summary of the Study}

The three parts included in this section will afford a concise restatement of the problem addressed in the study, a summary of the methodology employed, and a brief restatement of the specific research hypotheses tested and the statistical hypothesis developed to test for alternative explanations.

\section{Statement of the problem}

This study explored the relationships between the principals' emotional intelligence, leadership style and organizational culture in 57 elementary schools within Miami-Dade County Public Schools. Emotional intelligence was measured by the BarOn Emotional Quotient Inventory (EQ-i), a self-report survey completed by principals. The Multifactor Leadership Questionnaire (MLQ 5X) completed by the faculty of each participating principal was the measure of leadership style employed. Organizational culture was measured by faculty responses to the school district's School Climate Survey.

\section{Statement of the procedures}

A stratified random sampling technique was employed to select principals for participation in the study. Faculty surveys were sent to all teachers at each responding principal's school. Fifty seven principals and 850 teachers responded to the online 
surveys disseminated via the district's electronic mailing system. The first part of both online surveys included items requesting demographic information. The second part of the principals' surveys included all of the items and response options on the EQ-i. The second part of the teachers' surveys included all of the items and response options on the MLQ Form 5X. Survey responses were collected using the Qualtrics Survey Software. Faculty responses to the School Climate Survey were gathered from the district's web site. The specific research hypotheses developed were based on theoretical frameworks on emotional intelligence, leadership style and school culture presented in the literature. Linear regression analyses were conducted to examine the relationship between emotional intelligence and leadership style, as well as the interaction of emotional intelligence and leadership style in predicting school culture. Hierarchical regression analyses were utilized to explore the main effects of emotional intelligence and leadership style in predicting school culture.

\section{Specific Research Hypotheses}

The four specific research hypotheses tested were:

1. The EQ-i scores of elementary school principals account for a significant amount of unique variance in predicting their scores on the MLQ Form 5X.

2. The interaction between the EQ-i scores of public elementary school principals and their scores on the MLQ Form $5 \mathrm{X}$ accounts for a significant amount of unique variance in predicting school culture over and above the additives.

3. The public elementary school principals' scores on the MLQ Form 5X account for a significant amount of unique variance in predicting school culture over and above their EQ-i scores. 
4. The public elementary school principals' EQ-i scores account for a significant amount of unique variance in predicting school culture over and above their scores on the MLQ Form 5X.

Additionally, the following statistical hypothesis was utilized to test for alternative explanations:

Over and above the influence of school grade, scores on the MLQ Form 5X account for a significant amount of unique variance in predicting school culture.

\section{Conclusions}

The results of the linear regression analyses to test the first and second specific research hypotheses, and the hierarchical regression analyses conducted to test the third

and fourth specific research hypotheses provide support for conclusions drawn regarding the relationships between emotional intelligence, leadership style, and school culture explored in this study. The first hypothesis regarding the relationship between emotional intelligence and leadership style was partially supported. Three of the five dimensions of transformational leadership measured, Idealized Influence-Attributes, Idealized Influence-Behaviors, and Inspirational Motivation were found to be positively associated with emotional intelligence (see Table 8). The transactional leadership measure of Contingent Reward was also positively associated with emotional intelligence. These findings were consistent with prior studies conducted in corporate and retail settings in which Idealized Influence, Inspirational Motivation and Individual Consideration (Barling, Slater \& Kelloway, 2000; Leban \& Zulauf, 2004), and Contingent Reward (Harms and Credé, 2010) were positively related to emotional intelligence. These results suggest that emotional intelligence is positively related to dimensions of both 
transformational and transactional leadership, and solidify the positions espoused by theorists that emotional intelligence is an important aspect of effective leadership (BarOn, 1997; Brown \& Moshavi, 2005; Goleman, 1995; Prati, et al., 2003).

Because no significant associations were found between the interaction of emotional intelligence and leadership style in predicting school culture as stipulated in the second research hypothesis (see Table 9), the main effects of leadership and emotional intelligence in predicting school culture were examined. The outcomes of the hierarchical regression analysis to test the third research hypothesis revealed significant positive associations between transformational leadership and school culture over and above emotional intelligence (see Table 10). Specifically, positive associations were found between all dimensions of transformational leadership combined and both aspects of school culture, Teacher Professionalism and Goal Setting and Professional Treatment by Administrators. Idealized Influence-Attributes was also positively associated with Professional Treatment by Administrators, while the transactional measure of Contingent Reward was positively associated with both aspects of school culture (see Table 11). Additionally, significant negative associations were found between Intellectual Stimulation and the Passive-Avoidant measure of Laissez-faire and school culture over and above emotional intelligence (see Tables 10 and 12). These results support prior findings regarding the relationship between leadership style and school culture (Hallinger, 2003; Kelley, et al., 2005; Leithwood, 1994; Rud \& Garrison, 2010; Witziers et al., 2003).

The association between leadership style and school culture was further corroborated by the hierarchical regression analysis for the fourth research hypothesis 
testing the relationship between emotional intelligence and school culture over and above leadership style. This analysis revealed significant positive associations between emotional intelligence and both aspects of school culture, and yielded the same results regarding the associations between transformational and transactional leadership measures and school culture found when testing the third research hypothesis. Thus, both emotional intelligence and leadership style were positively associated with school culture. These findings, coupled with the positive associations between emotional intelligence and leadership style supported by this study, suggest that emotional intelligence can play a significant role in leadership theory as posited in the literature (Barbuto \& Burbach, 2006; Fullan, 2002; Harms \& Credé, 2010; Nelson et al., 2007, Weinberger, 2009).

\section{Discussion}

The utility of conclusions drawn from educational research lies in the implications that can be derived regarding theory, practice, research, and policy. The following section provides a discussion of the impact the results of this study may hold for each of these areas.

\section{Theoretical Implications}

The theory of transformational leadership was initially introduced from a narrow perspective in which leaders strictly focused on their followers' higher order needs as identified by Maslow and formed a symbiotic bond with them which elevated both leaders and followers to higher levels of moral consciousness (Burns, 1978). This perspective evolved, however, and subsequent theorists believe that transformational leaders also employ transactional practices (Barth, 2002; Bass \& Avolio, 1994; Fullan, 
2002; Hallinger, 2003; Leithwood, 1992, 1994). The results of this study provide support for this view. As evidenced by the summary of the mean scores on the MLQ Form $5 \mathrm{X}$ completed by teachers for the principals in this study (see Table 5), Contingent Reward, a measure of transactional leadership, ranked among the highest scores along with three aspects of transformational leadership. Thus, the principals in this study employ both transformational and transactional leadership practices, as predicted by Bass and Avolio (1994).

Leithwood and Jantzi (2005) espoused an expanded conceptualization of transformational leadership. They proposed that additional transformational behaviors such as vision, charisma, and goal setting, as well as transactional behaviors, should be employed, specifically within the context of schools. The results of this study support these theoretical implications that a broader conceptualization of transformational leadership is appropriate. Principals do not, and should not, limit the scope of their leadership strategies to focus solely on the higher order needs described by Maslow and Kohlberg as suggested by Burns (1978). It seems that in the current turbulent times within the field of education, in which political forces palpably infringe on the day-to-day operations of schools (Conley, 2003), principals must also consider the lower order needs of their followers and employ active elements of transactional leadership such as Contingent Reward. The theory of transformational leadership, then, is more appropriately defined in broader terms, as suggested by Bass and Avolio (1994), and by Hallinger (2003). Transformational leaders should be conceptualized as exhibiting a wider range of strategies that include a variety of both transformational and transactional practices. 
A similar debate regarding the breadth with which emotional intelligence is conceptualized is evident in the literature (Mayer et al., 2008). The broader perspective, defined as trait-based emotional intelligence (Bar-On, 1997), was adopted in this study. Because this broader trait-based view of emotional intelligence was found to be associated with both transformational leadership behaviors and active elements of transactional leadership in this study, this broader theoretical perspective of the construct seems to be more appropriate, as suggested by Petrides and Furnham (2001). The associations between emotional intelligence and transformational leadership found in this study also address a pressing question among scholars of leadership theory regarding the relationship between these two constructs (Antonakis, 2003; Brown \& Moshavi, 2005; Fullan, 2002; Prati, et al., 2003). Thus, the findings in this study contribute to the theoretical discussions present in the literature focused on the relationship between emotional intelligence and leadership. Moreover, these findings, coupled with Fullan's (2002) view that utilizing a transformational leadership style requires enhanced relationships between leaders and their followers, which is contingent upon the leaders' level of emotional intelligence, suggest that emotional intelligence is an antecedent to transformational leadership behaviors, as suggested by Brown and Moshavi (2005).

Theorists have also espoused that a reciprocal relationship exists between leaders and school culture (Witziers et al., 2003), and that leaders play a pivotal role in shaping their school's culture (Kelley, Thornton \& Daugherty, 2005). Recognizing that principals indirectly affect school improvement through their influence over school conditions, the focus of these discussions has been on the relationship between leadership style and school culture (Hallinger, 2003; Leithwood, 1994). Here again, the results of 
this study contribute to these theoretical views because a significant association was found between transformational leadership and school culture, as well as between Contingent Reward and school culture. However, the results of this study also supported the existence of a significant relationship between the principals' level of emotional intelligence and school culture. The theoretical implications of these findings would be that because leaders who exhibit a high level of emotional intelligence effectively perceive and understand others' emotions (Mayer \& Salovey, 1997), their followers' perceptions of school conditions could be enhanced. Consequently, in examining variables associated with school culture, it seems the principals' level of emotional intelligence also merits consideration.

\section{Practical Implications}

The theoretical implications that evolved from the results of this study also contain propositions that impact leadership practice. Specifically, school principals should adopt a broader leadership style that incorporates both transformational and transactional strategies, especially because Contingent Reward emerged as one of the individual measures of leadership that was positively associated with emotional intelligence and was a strong predictor of school culture. Thus, it seems that leaders who exhibit higher levels of emotional intelligence recognize that followers need rewards and recognition, and readily provide them. Principals would do well to do so, because this practice was found to be associated with teachers' perspective of their school's culture in this study. Moreover, researchers have agreed that transactional and transformational leadership practices are complementary, and that both should be employed (Bass \& Avolio, 1994; Leithwood, 1992). 
The relationship between leadership style and emotional intelligence supported by this study strengthens the perspective that emotional intelligence could be an antecedent of transformational leadership, and, as such, could play a vital role in leadership practice (Brown \& Moshavi, 2005; Nelson et al., 2007). These findings carry significant practical implications regarding the preparation and development of school leaders. Because researchers have posited that emotional intelligence is a skill that can be developed, enhancing the emotional intelligence of school principals could result in enhanced use of transformational leadership practices (Nelson et al., 2007). Additionally, because this study also revealed significant associations between emotional intelligence and school culture, enhancing the emotional intelligence of school leaders could also result in improved school culture. Thus, focusing on enhancing the emotional intelligence of school leaders within principal preparation and development programs could result in two positive outcomes.

The fact that no significant associations were found between the transformational measure of Individualized Consideration and emotional intelligence or school culture also contains practical considerations. This finding differs from the conclusions drawn by Leithwood (1994), in which Individualized Consideration was deemed to be the most influential aspect of transformational leadership in school settings. The question that emerges is, what changes occurred in this 20 -year span in the field of education that would lead to a reversal of these findings within the context of this study? The answer may very well lie in the model developed by Leithwood to demonstrate the effects of transformational leadership on school outcomes (Leithwood, 1994). This 
conceptualization recognizes that out of school conditions or outside forces also play a significant role in school outcomes.

A major outside force impacting schools that was not present in 1994 is the No Child Left Behind Act of 2001. This legislation and the resulting accountability measures developed and implemented in its aftermath, have become an intrusive force in schools, and have increasingly relegated the role of the principal to that of a middle manager with minimal or limited authority (Conley, 2003). In this climate, it may very well be that standards and policies imposed on schools limit a principal's ability to demonstrate Individualized Consideration toward teachers, or that teachers bound by these requirements do not perceive this quality from their principals. Regardless, the results of this study suggest that the combined strategies of transformational leadership practices along with Contingent Reward should be adopted by principals. Moreover, the results of this study, combined with the consideration of outside forces posited by Leithwood (1994), imply that by employing transformational leadership practices principals may successfully mitigate the effect of these out of school conditions.

Because researchers have found that positive school cultures are associated with student achievement (Witziers et al., 2003), a principal's ability to develop organizational culture becomes vital in school reform efforts. This study supports the association between transformational leadership and school culture supported by Hallinger (2003), who advocated for transformational leadership practices in schools. Researchers agree that transformational leadership practices, and the resulting relationships that develop between leaders and followers, are pivotal in navigating school reform (Fullan, 2002; Leithwood, 1992). The principals' level of emotional intelligence has also been 
considered to play a key role in leading teachers through the school reform process (Fullan, 2002; Goleman, 1998a), especially since it has been acknowledged that teachers' emotional reactions to the changes inherent in school reform efforts must be taken into consideration (Reio, 2005). This study also supports an association between the principals' level of emotional intelligence and school culture. Hence, practical implications for principals include employing both transformational leadership practices and active elements of transactional practices, as well as focusing on developing and enhancing their level of emotional intelligence because these variables were found to be positively associated with school culture. Adopting these practices could enhance principals' abilities to facilitate the school reform process for their teachers.

\section{Implications for Policy}

Policies governing schools have become increasingly more intrusive since the age of accountability spawned by the No Child Left Behind Act of 2001 (Conley, 2003). This politically charged climate has also impacted the leadership practices believed to be effective and appropriate for principals (Hallinger, 2003). In the 1980s, the take-charge methodology in which principals were directly involved with curriculum and instruction and implemented a top-down approach to school management known as instructional leadership was prevalent (Hallinger, 2003; Leithwood, 1994). In the 1990s this philosophy gave way to the concepts of shared and distributed leadership in which the principal was no longer the central figure, and transformational leadership practices were expected (Harris, 2004; Henkin, Cistone \& Dee, 2000; Sergiovanni, 2004). However, the stringent accountability measures currently governing school policy seem to have caused the pendulum to swing back toward a more direct approach to leadership. Although, 
within this climate, state boards of education direct local school boards to employ differentiated accountability measures and become increasingly more involved in actually running the schools. As a result, the principals' role has been diminished to that of middle manager (Conley, 2003). These policies are contra-indicated in light of the findings supported by this study and by other researchers regarding the principal's role (Fullan, 2002; Hallinger, 2003; Leithwood, 1994; Reio, 2005).

Researchers agree that school reform is more effectively achieved through the principal's ability to successfully implement "second order" change, in which organizational outcomes are achieved by influencing the organization itself and the people within it (Leithwood, 1994; Witziers et al., 2003). This perspective is aligned with transformational leadership theory (Bass \& Avolio, 1994; Burns, 1978; Hallinger, 2003), and is supported by the findings in this study. The associations between emotional intelligence, transformational leadership, Contingent Reward and school culture found in this study validate the role of the principal as the leader of school reform. The principals' level of emotional intelligence is essential in considering teachers' emotional reactions to change (Fullan, 2002; Goleman, 1998a; Reio, 2005), and is positively associated with school culture as revealed in this study. Theoretically, transformational leadership practices positively influence school culture, which encompasses elements of the professionalization of teaching that are at the core of school restructuring (Leithwood, 1994). Given these findings, and the theoretical positions espoused by these researchers, school districts would do well to re-examine policies that result in mitigating the principals' role, and instead focus on empowering principals to lead school reform efforts. District policies should also incorporate principal development and principal 
preparation programs designed to enhance emotional intelligence, and leadership skills that integrate transformational and active elements of transactional practices.

\section{Implications for Research}

Researchers are divided regarding the appropriate approach toward examining the relationship between emotional intelligence and transformational leadership. Some researchers have called for additional studies to clarify the nature of the relationship between these constructs (Brown \& Moshavi, 2005). Others have stressed the importance of conducting additional research and provided a conceptual model to guide future studies (Prati et al., 2003). In contrast, Antonakis (2003) advocated that engaging in empirical research in search of support for such a relationship is premature and unwarranted. This study contributes to the body of research regarding these relationships. Because significant associations were found between emotional intelligence and transformational leadership, the findings substantiate the views espoused by Brown and Moshavi (2005) and Prati (2003) and colleagues.

This study also addressed methodological concerns expressed by Lindebaum and Cartwright (2010) regarding common method bias. Researchers have questioned whether the associations found between emotional intelligence and transformational leadership in prior studies reflect true associations or are affected by methodology in which both constructs are measured through self-report surveys completed by principals. Recognizing this concern, this study employed two different data sources to measure these constructs. Emotional intelligence was measured through a self-report survey completed by principals, while leadership style and school culture were measured through surveys completed by teachers. This study revealed support for associations 
between emotional intelligence and leadership style while controlling for the concerns expressed by researchers regarding common method bias (Lindebaum \& Cartwright, 2010).

\section{Suggested Further Research}

As in most studies, while some questions posited were answered, and while conclusions and implications could be derived from the relationships uncovered, other questions emerge and relevant further research can be suggested. The following are recommendations for further research that would be of value in expanding upon the findings presented in this study.

1. Because this study was limited to elementary schools, additional research exploring the relationships between emotional intelligence, leadership style and school culture could be conducted in secondary schools, thereby expanding the generalizability of the findings.

2. The generalizability of these findings could also be expanded by replicating this study to test the model in different contexts, such as different geographic regions within the United States, or in different countries.

3. The model proposed in this study could also be tested with a larger $N$ size to explore whether the findings presented here can be supported.

4. The implications of this study suggest that outside forces may have impacted the degree to which principals' leadership style is associated with teachers' perceptions of school culture. A qualitative study could be conducted to explore principals' and teachers' perspectives on the role of principals within the context 
of increasingly stringent accountability standards that continue to be imposed on schools.

5. Accountability standards imposed on schools results in districts employing differentiated support strategies that limit or restrict the role of the principal to a greater degree in low performing schools. Only one of the 57 schools included in this study was considered a low performing school based on Florida's Accountability Reports. Further research could be conducted in low performing schools to explore the relationships between the principals' level of emotional intelligence, leadership style and school culture within contexts in which outside forces have a greater influence on the daily operations of the school.

6. The Multifactor Leadership Questionnaire also includes items designed to gauge the outcome variables of teachers' perspectives on the principals' effectiveness. These variables were not included in this study. Further research could explore the relationship between these outcome variables of the principals' effectiveness, emotional intelligence and school culture.

\section{Summary}

Chapter 5 concludes this study with a summary of the purpose, and restatement of the problem, procedures and results. The findings revealed that principals who employ transformational leadership practices also employ the transactional strategy of Contingent Reward. Additionally, support was found for a relationship between emotional intelligence, transformational leadership, Contingent Reward, and school culture.

These findings suggest that emotional intelligence can play a significant role in leadership theory, and that a broader conceptualization of both emotional intelligence and 
transformational leadership is more appropriate within school settings. Practical implications include the possibility of developing the emotional intelligence of school leaders in order to enhance their leadership style to include transformational strategies, and in order to enhance school culture. Additionally, the use of both transformational leadership and Contingent Reward should be practiced. School policy makers should consider the results of this study in planning for school reform and school restructuring. The relationships uncovered among these variables suggest that principals could play a pivotal role in leading teachers through the changes inherent in school reform efforts aimed at improved student achievement. 


\section{REFERENCES}

Antonakis, J. (2003). Why "emotional intelligence" does not predict leadership effectiveness. International Journal of Organizational Analysis, 11(4), 353-359.

Barbuto, J. E., \& Burbach, M. E. (2006). The emotional intelligence of transformational leaders: A field study of elected officials. The Journal of Social Psychology, 146(1), 51-64.

Barling, J., Slater, F., \& Kelloway, E. K. (2000). Transformational leadership and emotional intelligence: an exploratory study. Leadership \& Organization Development Journal, 21(3), 157-161.

Barth, R. (2002). The culture builder. Educational Leadership, 59(8), 6-11.

Bar-On, R. (1997). The emotional quotient inventory (EQ-i). Technical manual. Toronto, Canada: Multi-Health Systems.

Bar-On, R. (2007). How important is it to educate people to be emotionally intelligent, and can it be done? In R. Bar-On, J.G. Maree, \& M.J. Elias (Eds.), Educating people to be emotionally intelligent, (pp. 1-14). Westport, CN:Praeger.

Bar-On, R. (2011). EQ-i 2.0 user's handbook. Toronto, Canada: Multi-Health Systems.

Bass, B.M., \& Avolio, B.J. (1990). Transformational leadership development: Manual for the Multifactor Leadership Questionnaire. Palo Alto, CA: Consulting Psychologists Press.

Bass, B.M., \& Avolio, B.J. (1993). Transformational leadership and organizational culture. Public Administration Quarterly, 17(1), 112-121.

Bass, B.M., \& Avolio, B.J. (1994). Improving Organizational Effectiveness Through Transformational Leadership. London, England: Sage.

Bass, B.M., \& Avolio, B.J. (2004). Multifactor leadership questionnaire manual and sample set ( $3^{\text {rd }}$ ed.). Menio Park, CA: Mind Garden.

Bogler, R. (2001). The influence of leadership style on teacher job satisfaction. Educational Administration Quarterly, 37(5), 662-683.

Bolman, L. G., \& Deal, T. E. (2002). Leading with soul and spirit. School Administrator, 59(2), 21-26.

Bolman, L.G., \& Deal T.E. (2008). Reframing Organizations: Artistry, choice, and leadership. San Francisco, CA: Jossey-Bass. 
Brackett, M.A., \& Mayer, J.D. (2003). Convergent, discriminant, and incremental validity of competing measures of emotional intelligence. Personality and Social Psychology Bulletin, 29, 1-12.

Brown, F.W., \& Moshavi, D. (2005). Transformational leadership and emotional intelligence: a potential pathway for an increased understanding of interpersonal influence. Journal of Organizational Behavior, 26, 867-871.

Burns, J.M. (1978). Leadership. New York, NY: Harper \& Row.

Butler, C.J., \& Chinowsky, P.S. (2006). Emotional intelligence and leadership behavior in construction executives. Journal of Management in Engineering, 22, 119-25.

Cheng, Y.C. (1993). Profiles of organizational culture and effective schools. School Effectiveness and School Improvement: An International Journal of Research, Policy and Practice, 4(2), 85-110.

Cistone, P.J., \& Stevenson, J.M. (2000). Perspectives on the urban school principalship. Education and Urban Society, 32(4), 435-442.

Cohen, J. (1977). Statistical power analysis for the behavioral sciences (Rev. Ed.), New York, NY: Academic Press.

Conley, D.T. (2003). Who governs our schools? Changing roles and responsibilities. New York: Teachers College Press.

Cronbach, L. (1951). Coefficient alpha and the internal structure of tests. Psyochemtrica, 16, 527-530.

Davies, B., \& Brighouse, T. (2010). Passionate leadership. Management in Education, 24(1), 4-6.

Duckett, H., \& Macfarlane, E. (2003). Emotional intelligence and transformational leadership in retailing. Leadership and Organization Development Journal, 24, 309-17.

Edwards, J.L., Green, K.E., \& Lyons, C.A. (1996, April). Factor and rasch analysis of the school culture survey, paper presented at the Annual Meeting of the American Educational Research Association, New York, NY.

Florida Department of Education (2013). School Accountability Reports. Retrieved November 22, 2013 from http://schoolgrades.fldoe.org/

Fullan, M. (2002). The change leader. Educational leadership, 59(8), 16-20. 
Fullan, M. (2001). The new meaning of educational change ( $3^{\text {rd }}$ ed.). New York, NY: Teachers College Press.

Gardner, H. (1983). Frames of mind. New York, NY: Basic Books.

Goleman, D. (1995). Emotional intelligence: Why it can matter more than IQ. New York, NY: Bantam Books.

Goleman, D. (1998a). What makes a leader? Harvard Business Review, 76, 93-102.

Goleman, D. (1998b). Working with emotional intelligence. New York, NY: Bantam.

Hallinger, P. (2003). Leading educational change: reflections on the practice of instructional and transformational leadership. Cambridge Journal of Education, 33(3), 329-51.

Harms, P. D., \& Credé, M. (2010). Emotional intelligence and transformational and transactional leadership: A meta-analysis. Journal of Leadership \& Organizational Studies, 17(1), 5-17.

Harris, A. (2004). Distributed leadership and school improvement: Leading or misleading? Educational Management Administration \& Leadership, 32(1), 11 24.

Henkin, A.B., Cistone, P.J., \& Dee, J.R. (2000). Conflict management strategies of principals in site-based managed schools. Journal of Educational Administration, 38(2), 142-158.

Horng, E. L., Klasik, D., \& Loeb, S. (2010). Principal's time use and school effectiveness. American Journal of Education, 116(4), 491-523.

Hoy, W. K., \& Miskel, C. G. (2008). The school as a social system. In Educational administration. Theory, research, and practice. ( $8^{\text {th }}$ ed., 2-23). Boston, MA: McGraw Hill.

Johnson, C. (2012). Meeting the ethical challenges of leadership. Casting light or shadow. ( $4^{\text {th }}$ ed.) Los Angeles: Sage.

Kelley, R. C., Thornton, B., \& Daugherty, R. (2005). Relationships between measures of leadership and school climate. Education, 126(1), 17.

Leban, W., \& Zulauf, C. (2004). Linking emotional intelligence abilities and transformational leadership styles. Leadership and Organization Development Journal, 25, 554-64. 
Leithwood, K. (1994). Leadership for school restructuring. Educational Administration Quarterly, 30(4), 498-518.

Leithwood, K. A. (1992). The move toward transformational leadership. Educational Leadership, 49(5), 8-12.

Leithwood, K., \& Jantzi, D. (2005). A review of transformational school leadership research 1996-2005. Leadership and policy in schools, 4(3), 177-199.

Leithwood, K., Leonard, L., \& Sharratt, L. (1998). Conditions fostering organizational learning in schools. Educational Administration Quarterly, 34(2), 243-276.

Lindebaum, D., \& Cartwright, S. (2010). A critical examination of the relationship between emotional intelligence and transformational leadership. Journal of Management Studies, 10, 1317-1342.

Lumpkin, A. (2008). Three keys to success for principals (and their teachers). Kappa Delta Pi Record, 45(1), 22-25.

Marks, H., \& Printy, S. (2003). Principal leadership and school performance: an integration of transformational and instructional leadership. Educational Administration Quarterly, 39(3), 370-397.

Maslow, A.H. (1943). A theory of human motivation. Psychological Review, 50, 370396.

Maslowski, R. (2006). A review of inventories for diagnosing school culture. Journal of Educational Administration, 44(1), 6-35.

Maslowski, R. (2001). School culture and school performance. An explorative study into the organizational culture of secondary schools and their effects. Enschede, the Netherlands: Twente University Press.

Mayer, J. D., Caruso, D. R., \& Salovey, P. (2000). Emotional intelligence meets traditional standards for an intelligence. Intelligence, 27(4), 267-298.

Mayer, J. D., \& Salovey, P. (1993). The intelligence of emotional intelligence. Intelligence, 17(4), 433-442.

Mayer, J.D., \& Salovey, P. (1997). What is emotional intelligence? In P. Salovey \& D. Sluyter (Eds.), Emotional development and emotional intelligence: Educational implications (pp. 3-31). New York, NY: Basic Books.

Mayer, J. D., Salovey, P., \& Caruso, D. R. (2008). Emotional intelligence: new ability or eclectic traits? American Psychologist, 63(6), 503. 
McNeil, K., Newman, I., \& Fraas, J.W. (2012). Designing general linear models to test research hypotheses. New York, NY: University Press of America.

Nelson, D.B., \& Low, G.R. (2003). Emotional intelligence: Achieving academic and career excellence, Upper Saddle River, NJ: Prentice Hall.

Nelson, D., Low, G., \& Ellis, R. (2007). Emotional intelligence: A transformative theory and applied model of positive personal change. Annals of the American Psychotherapy Association, 10(4), 30-35.

Newman, I., \& Newman, C. (2005). Conceptual Statistics for Beginner ( $2^{\text {nd }}$ ed.). New York, NY: University Press of America, Inc.

Ogbonna, E., \& Harris, L.C. (2000). Leadership style, organizational culture and performance: empirical evidence from UK companies. International Journal of Human Resource Management, 11(4), 766-788.

Peterson, K. D., \& Deal, T. E. (1998). How leaders influence the culture of schools. Educational Leadership, 56(1), 28-30.

Petrides, K. V., \& Furnham, A. (2001). Trait emotional intelligence: Psychometric investigation with reference to established trait taxonomies. European Journal of Personality, 15(6), 425-448.

Petrides, K. V., \& Furnham, A. (2003). Trait emotional intelligence: Behavioural validation in two studies of emotion recognition and reactivity to mood induction. European Journal of Personality, 17(1), 39-57.

Prati, L.M., Douglas, C., Ferris, G.R., Ammeter, A.P., \& Buckley, M.R. (2003). Emotional intelligence, leadership effectiveness, and team outcomes. The International Journal of Organizational Analysis, 11(1), 21-40.

Reio Jr, T. G. (2005). Emotions as a lens to explore teacher identity and change: A commentary. Teaching and Teacher Education, 21(8), 985-993.

Rogelberg, S.G., \& Luong, A. (1998). Nonresponse to mailed surveys: a review and guide. Current Directions in Psychological Science, 7(2), 60-65.

Rud, A. G., \& Garrison, J. (2010). Leading schools with reverence. Educational Forum, 74(2), 143-157.

Salovey, P., \& Mayer, J.D. (1990). Emotional intelligence. Imagination, Cognition and Personality, 9(3), 185-211. 
Saphier, J., \& King, M. (1985). Good seeds grow in strong cultures. Educational Leadership, 42(6), 67-74.

Schein, E. H. (1996). Culture: The missing concept in organization studies.

Administrative Science Quarterly, 229-240.

Schein, E.H. (1985). Organizational culture and leadership. San Francisco, CA: Jossey-Bass.

Sergiovanni, T. J. (2004). Collaborative cultures and communities of practice. Principal Leadership, 5(1), 48-52.

Sergiovanni, T. J. (2005). The virtues of leadership. The Educational Forum, 69(2), 112123.

Thorndike, E.L. (1920). Intelligence and its uses. Harper's Magazine, 140, 227-335.

Thorndike, R.L., \& Stein, S. (1937). An evaluation of the attempts to measure social intelligence. Psychological Bulletin, 34, 275-284.

Trochim, W.M.K., \& Donnelly, J.P. (2008). Research methods knowledge base ( ${ }^{\text {rd }}$ ed.). Mason: Cengage Learning.

Van Rooy, D. L., \& Viswesvaran, C. (2007). Assessing emotional intelligence in adults: A review of the most popular measures. In Educating people to be emotionally intelligent, (chap. 18). Westport, Conn: Praeger Publishers.

Vera, D., \& Crossan, M. (2004). Strategic leadership and organizational learning. Academy of Management Review, 29(2), 222-240.

Weinberger, L.A. (2009). Emotional intelligence, leadership style, and perceived leadership effectiveness. Advances in Developing Human Resources, 11(6), 747772 .

Witziers, B., Bosker, R. J., \& Kruger, M. L. (2003). Educational leadership and student achievement: The elusive search for an association. Educational Administration Quarterly, 39(3), 398-425.

Woodruff, P. 2001. Reverence: Renewing a forgotten virtue. New York: Oxford University Press. 


\section{Appendix A}

\section{Informational Letter}

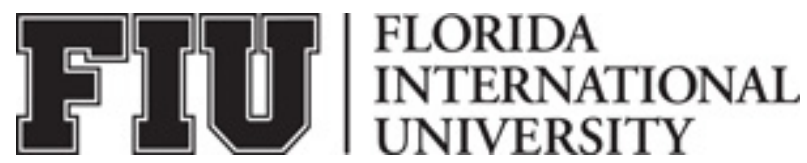

INFORMATIONAL LETTER

The Relationship between Emotional Intelligence and

Transformational Leadership: A Means of Predicting School Culture

You are being asked to participate in a research study about leadership style and school culture. The investigator in this study is Mirta Segredo, a student at Florida International University. The purpose of this study is to investigate the relationships between emotional intelligence, transformational leadership and school culture. Emotional intelligence refers to the ability to understand and regulation one's emotions, and to understand the emotions of others. Transformational leadership can be described as a process where leaders and followers raise one another to higher levels of motivation, and has been credited with building a strong organizational culture.

If you decide to be a part of this study, you will be one of 60 principals, or 1,200 teachers in this research study. Participation in this study will take approximately 30 minutes of your time. Your participation will involve completing a questionnaire. You may skip any questions that you do not want to answer. There are no foreseeable risks or benefits to you for participating in this study. There is no cost or payment to you. However, it is expected that this study will benefit the field of education by providing information regarding the relationships between emotional intelligence, leadership style and school culture.

You will remain anonymous. A generic number and not your name will identify your responses. Your responses are private and will not be shared with anyone. You may ask questions about the study at any time. There will be no negative consequences if you choose not to participate. You may also choose to stop your participation before finishing the questionnaire.

If you would like more information or have any questions about this research study, you may contact Mirta Segredo at If you would like to talk with someone about your rights of being a subject in this research study or about ethical issues with this research study, you may contact the FIU Office of Research Integrity by phone at 305-348-2494 or by email at ori@fiu.edu.

Your participation in this research is voluntary, and you will not be penalized or lose benefits if you refuse to participate or decide to stop. You may keep a copy of this form for your records. 
VITAE

MIRTA R. SEGREDO

Born, Havana, Cuba

1981

B.S., Elementary Education

Florida International University

Miami, Florida

$1981-1993$

Teacher

Miami-Dade County Public Schools

Miami, Florida

1984

M.S., Elementary Education

Nova Southeastern University

Fort Lauderdale, Florida

1992

$1991-1992$

Educational Leadership Certification Program

Florida International University

Miami, Florida

Trainer and Curriculum Developer for

Teacher Workshops, Methods of Teaching E.S.O.L.

Training Institute for Educators

Florida International University

Miami, Florida

$1993-2001$

Assistant Principal

Miami-Dade County Public Schools

Miami, Florida

2001 - Present

Principal

Miami-Dade County Public Schools

Miami, Florida

Summer 2010 - Summer 2014

Doctoral Candidate

Educational Administration and Supervision

Florida International University

Miami, Florida

2011 - Present

Adjunct Faculty

College of Education

Florida International University

Miami, Florida 


\section{PUBLICATIONS AND PRESENTATIONS}

Reio, T.G., and Segredo, M.R. (2013). The Role of Mentoring on Teacher Turnover Intent Among Middle School Teachers. Paper presented at the 2013 American Educational Research Association (AERA) Annual Meeting. San Francisco, California.

Reio, T.G., and Segredo, M.R. (2013). The Role of Mentoring on Teacher Turnover Intent Among Middle School Teachers. Paper presented at the South Florida Educational Research Conference. Miami, Florida. 